\title{
X-linked histone H3K27 demethylase Kdm6a regulates sexually dimorphic differentiation of hypothalamic neurons
}

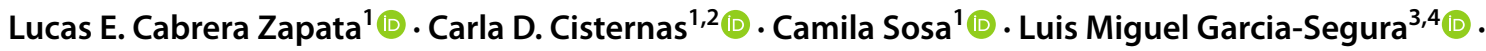 \\ Maria Angeles Arevalo ${ }^{3,4}$ [D $\cdot$ María Julia Cambiasso ${ }^{1,2}$ (D)
}

Received: 31 May 2021 / Revised: 26 August 2021 / Accepted: 17 September 2021 / Published online: 11 October 2021

(c) The Author(s) 2021

\begin{abstract}
Several X-linked genes are involved in neuronal differentiation and may contribute to the generation of sex dimorphisms in the brain. Previous results showed that XX hypothalamic neurons grow faster, have longer axons, and exhibit higher expression of the neuritogenic gene neurogenin $3(\mathrm{Ngn} 3)$ than XY before perinatal masculinization. Here we evaluated the participation of candidate X-linked genes in the development of these sex differences, focusing mainly on Kdm6a, a gene encoding for an H3K27 demethylase with functions controlling gene expression genome-wide. We established hypothalamic neuronal cultures from wild-type or transgenic Four Core Genotypes mice, a model that allows evaluating the effect of sex chromosomes independently of gonadal type. X-linked genes Kdm6a, Eif2s $3 x$ and $D d x 3 x$ showed higher expression in XX compared to XY neurons, regardless of gonadal sex. Moreover, $K d m 6 a$ expression pattern with higher mRNA levels in XX than XY did not change with age at E14, P0, and P60 in hypothalamus or under 17 $\beta$-estradiol treatment in culture. Kdm6a pharmacological blockade by GSK-J4 reduced axonal length only in female neurons and decreased the expression of neuritogenic genes Neurodl, Neurod 2 and $C d k 5 r l$ in both sexes equally, while a sex-specific effect was observed in Ngn3. Finally, Kdm6 $a$ downregulation using siRNA reduced axonal length and $N g n 3$ expression only in female neurons, abolishing the sex differences observed in control conditions. Altogether, these results point to $K d m 6 a$ as a key mediator of the higher axogenesis and $\mathrm{Ngn} 3$ expression observed in $\mathrm{XX}$ neurons before the critical period of brain masculinization.
\end{abstract}

Keywords Kdm6a $\cdot$ H3K27 demethylation $\cdot$ Sex differences $\cdot$ Ngn3 $\cdot$ Neuritogenesis $\cdot$ Hypothalamic neurons

\section{Introduction}

The brain is a sexually dimorphic organ, along with many other organs and tissues besides the gonads. These sex differences are found on a wide range of levels, both in the biochemical and architectural nature of certain brain regions

Maria Angeles Arevalo

arevalo@cajal.csic.es

$\triangle$ María Julia Cambiasso

jcambiasso@immf.uncor.edu

1 Instituto de Investigación Médica Mercedes y Martín Ferreyra, INIMEC-CONICET, Universidad Nacional de Córdoba, 5016 Córdoba, Argentina

2 Cátedra de Biología Celular, Facultad de Odontología, Universidad Nacional de Córdoba, 5000 Córdoba, Argentina

3 Instituto Cajal, CSIC, 28002 Madrid, Spain

4 CIBERFES, Instituto de Salud Carlos III, 28029 Madrid, Spain and, consequently, in the physiological and behavioral responses controlled by such dimorphic regions, as well as in the susceptibility to certain neurodevelopmental, psychiatric, and neurodegenerative diseases, such as autism spectrum disorders, dyslexia, depression and anxiety disorders, attention deficit hyperactivity disorder, schizophrenia, and dementia, among others [1,2]. Two major factors are currently known to contribute to the setting of sexual dimorphisms in the brain during development: (1) a sex-specific trophic environment due to differences in gonadal hormones secretion and (2) a distinct genetic and epigenetic pattern for males and females generated by differences in the expression of $\mathrm{X}$ and $\mathrm{Y}$ chromosomes-linked genes [3-5].

$\mathrm{X}$ and $\mathrm{Y}$ chromosomes have undergone a divergent evolutionary process, determining that they currently encode mostly dissimilar genetic information and are subject to different epigenetic regulations. As a result, these chromosomes are no longer capable of recombining during meiosis along most of their length except for the pseudoautosomal 
regions (PARs), the small regions of sequence identity at the termini of both $\mathrm{X}$ and $\mathrm{Y}$. Therefore, the intermediary regions between the PARs that cannot recombine, called the nonPAR of the $\mathrm{X}$ and the male-specific region of the $\mathrm{Y}$ (MSY), encompass most of both chromosomes and encode genes that are $\mathrm{X}$ - and Y-specific, respectively [6, 7]. Although $\mathrm{X}$-linked genes are present in both sexes, the existence of two $\mathrm{X}$ in every cell of females and only one in males generates a "dosage difference" in the copy number of virtually all of these genes between the sexes. This imbalance is compensated during development by the $\mathrm{X}$ chromosome inactivation mechanism (XCI), which involves the transcriptional silencing of one of the two Xs in each cell of an XX embryo, thus defining an inactive (Xi) and an active (Xa) X chromosome that will be inherited through the successive mitotic divisions to all the cells that finally shape that individual [8-11]. However, XCI does not lead to complete repression of all genes in the $\mathrm{Xi}$, but some "escape" inactivation and are therefore expressed from both Xa and Xi [12-15].

$K d m 6 a$ is an XCI "escapee" located on the non-PAR of the $\mathrm{X}$ that encodes for the lysine demethylase 6a (Kdm6a) or Utx enzyme, a member of the Kdm6 subfamily of histone 3 (H3) demethylases that remove di- (me2) and trimethyl (me3) groups on lysine (K) at position 27 (H3K27me2/ me3) [16]. H3K27me2/me3 are epigenetic marks known to repress gene expression, so their removal by Kdm6 demethylases promotes transcription [17-19]. Along with Kdm6a, the other two members of the Kdm6 subfamily are lysine demethylase $6 \mathrm{~b}$ (Kdm6b) or Jmjd3, encoded on autosome 11, and lysine demethylase 6c (Kdm6c) or Uty, a Kdm6a paralogue encoded on the MSY [16, 19, 20]. Kdm6a plays a key role in cell fate determination and cellular identity during development by controlling pluripotency and lineagespecific sets of genes [21, 22]. During brain development, $\mathrm{Kdm} 6 \mathrm{a}$ is involved in neurogenesis promotion, determining the neural stem cell status and modulating the subsequent differentiation of these pluripotent cells into neurons and glia [23-26]. Regarding neuronal differentiation, it has been shown that Kdm6a deletion prevents the proper development and maturation of neurons, leading to a repression of genes required for neuritogenesis and synaptogenesis (such as CREB 5, CAMK2A, CKB, ASIC1, and ASCL1, among many others), defects and immaturity in dendritic arborization and synapse formation, failures in electrophysiological activity, increased expression of anxious behaviors, and deficits in spatial learning and memory [27, 28]. Finally, $K d m 6 a$ constitutive mutations with loss of function lead to Kabuki syndrome, a congenital disorder characterized by intellectual disability accompanied by growth retardation and skeletal, cardiac, and facial abnormalities, among other manifestations [29-31].

The use of the Four Core Genotypes (FCG) transgenic mice allows independent evaluation of sex hormones and $\mathrm{X}$ and Y chromosomes effects on sexual differentiation. FCG model conjugates the deletion of the testis-determining Sry gene from the Y chromosome [32] with the reinsertion of this gene into autosome 3 [33]. This way, it was possible to unlink the inheritance of the $\mathrm{Y}$ chromosome from the inheritance of Sry and testis differentiation, obtaining four distinct genotypes: $\mathrm{XX}$ males (XXm) and females (XXf) and $\mathrm{XY}$ males (XYm) and females (XYf). Our previous results using FCG mice showed that sex chromosome complement (XY/XX) determines a sexually dimorphic expression of the proneural basic Helix-Loop-Helix transcription factor neurogenin 3 (Ngn3), with XX hypothalamic neurons presenting higher levels of Ngn3 mRNA than XY neurons, independently of gonadal sex [34]. In turn, XX neurons showed faster growth and maturation in vitro than $\mathrm{XY}$ neurons, a characteristic that was dependent on the higher $\mathrm{Ngn} 3$ expression in XX cultures [34, 35]. These and other results [36-41] point to the importance of sex chromosome complement in the sexual differentiation of the brain, regulating the expression of autosomal genes involved in neurodevelopment and modulating neuronal differentiation in a sex-specific way independently of sex hormones. However, although it is clear that sex chromosomes determined the sexual dimorphisms observed in Ngn 3 expression and neuronal growth and differentiation, the identity of particular $\mathrm{X}$ and Y-linked genes taking part in these processes remains unknown. Therefore, in the present study we aimed to evaluate specific X-linked genes participation in the sexually dimorphic differentiation of hypothalamic neurons, focusing on Kdm6a as a genomewide regulator of gene expression that escapes XCI and has a significant role in neurogenesis and neuritogenesis.

\section{Materials and methods}

\section{Animals}

FCG transgenic mice generated from MF1 strain (MF1-FCG mice, kindly donated by Dr. Paul Burgoyne, National Institute for Medical Research, London, UK), MF1 wild-type mice (Harlan Laboratories Inc., USA), and CD1 wild-type mice were used. MF1-FCG and MF1 wild-type mice were bred at the Instituto M. y M. Ferreyra (INIMEC-CONICETUniversidad Nacional de Córdoba, Córdoba, Argentina), whereas CD1 mice were obtained from colonies bred at both the Instituto M. y M. Ferreyra and the Instituto Cajal (CSIC, Madrid, Spain). Embryos used in FCG cultures were produced by breeding transgenic MF1-FCG XYm mice with wild-type MF1 females. Animals were kept in specific pathogen-free (SPF) conditions in individually ventilated cages until crosses were made to obtain pregnant females for experiments, at which time animals were placed in open cages. In all cases, the animals received water and food 
ad libitum and were kept in controlled macroenvironmental conditions of temperature at $23{ }^{\circ} \mathrm{C}$ and a $12 \mathrm{~h}$ light $/ 12 \mathrm{~h}$ dark periodic cycle. Procedures for care, welfare and proper use of all experimental animals were approved and controlled by the Institutional Animal Care and Use Committee (CICUAL) of the Instituto M. y M. Ferreyra, following national and international regulations, and were in accordance with the Consejería del Medio Ambiente y Territorio (Comunidad de Madrid, Ref. PROEX 200/14), the European Commission (86/609/CEE and 2010/63/UE), and the Spanish Government Directive (R.D.1201/2005) guidelines. FCG animals genotyping was performed by Polymerase Chain Reaction (PCR) as previously described in Cisternas et al. [41].

\section{Hypothalamic neuronal cultures and cell treatments}

FCG or CD1 wild-type embryos at 14 days of gestation (E14, defining E0 as the day of the vaginal plug) were used to establish primary hypothalamic neuronal cultures. Donor embryos age was specifically selected with the purpose of avoiding exposure of neurons to the peak in gonadal testosterone secretion during in utero development, which occurs in male mice around E17 [42]. Pregnant mice were sacrificed by cervical dislocation under $\mathrm{CO}_{2}$ anesthesia, and embryos were dissected from the uterus. Neurons were cultured separately according to sex (by observing the presence/ absence of the spermatic artery in developing gonads) or genotype (by PCR) of embryos. The ventromedial hypothalamic region was dissected out and stripped off the meninges. Blocks of tissue were incubated for $15 \mathrm{~min}$ at $37^{\circ} \mathrm{C}$ with $0.5 \%$ trypsin (Gibco, USA) and then washed three times with $\mathrm{Ca}^{2+} / \mathrm{Mg}^{2+}$-free Hank's Buffered Salt Solution. Finally, tissue was mechanically dissociated to single cells in $37^{\circ} \mathrm{C}$ warm culture medium and cells were seeded. The medium was phenol red-free Neurobasal (Gibco) to avoid "estrogenlike effects" [43] and was supplemented with B-27, 0.043\% L-alanyl-L-glutamine (GlutaMAX-I), $100 \mathrm{U} / \mathrm{ml}$ penicillin, and $100 \mathrm{mg} / \mathrm{ml}$ streptomycin (Gibco). For gene expression analyses, cells were plated on $35 \mathrm{~mm} \times 10 \mathrm{~mm}$ dishes (Corning, USA) or 6-wells plates (Falcon, USA) at a density of 500-1000 neurons $/ \mathrm{mm}^{2}$. To study the effect of Kdm6 H3K27 demethylase activity inhibition on gene expression, after 2 days in vitro (DIV) some cultures were treated with $1.8 \mu \mathrm{M}$ GSK-J4 (Sigma-Aldrich, USA) or vehicle for $24 \mathrm{~h}$. To study the effect of $17 \beta$-estradiol (E2) on Kdm6a expression, after 3 DIV the medium of some cultures was replaced for $2 \mathrm{~h}$ by a fresh medium devoid of B-27 and GlutaMAXI supplement and then cells were incubated for $2 \mathrm{~h}$ with $10^{-10}$ M E2 (Sigma-Aldrich) or vehicle. For morphometric analysis, cells were plated on $10 \mathrm{~mm}$ glass coverslips (Assistent, Germany) at a density of 800 cells $/ \mathrm{mm}^{2}$. After 3 DIV, some cultures were treated with $1.8 \mu \mathrm{M}$ GSK-J4 or vehicle for $24 \mathrm{~h}$. The surfaces of glass coverslips and plates were pre-coated with $1 \mu \mathrm{g} / \mu \mathrm{l}$ poly-L-lysine (Sigma-Aldrich).

\section{RNA isolation and quantitative Real-Time PCR (qPCR)}

Total RNA was extracted from cell cultures and hypothalamic tissue using TRIzol reagent (Invitrogen, USA), purified, and quantified by spectrophotometry on NanoDrop 2000 (Thermo Fisher Scientific, USA) as previously described [41]. $1 \mu \mathrm{g}$ of RNA per sample was reverse transcribed to cDNA in a $20 \mu \mathrm{l}$ reaction using M-MLV reverse transcriptase (Promega, USA) and random primers (Invitrogen), following manufacturer's instructions. qPCR reactions were performed on a StepOne Real-Time PCR System using TaqMan or SYBR Green Universal PCR Master Mix (Applied Biosystems, USA) and Rn18s (18S rRNA) as control housekeeping gene. TaqMan probes and primers for $\mathrm{Ngn} 3$ were assay-on-demand gene expression products (Applied Biosystems). All other primers (Table 1) were designed using the on-line Primer-Basic Local Alignment Search Tool (Primer-BLAST; National Institutes of Health, USA), selecting primer pairs spanning an exon-exon junction to restrict amplification specifically to mRNA. Primers were verified to amplify with a $95-100 \%$ efficiency by performing 4-point calibration curves. Relative quantification of mRNA expression was determined with the $\Delta \Delta \mathrm{Ct}$ method. Control XYm or control male samples were used as a reference group for experiments with FCG or wild-type mice, respectively.

\section{Small interfering RNA (siRNA) transfection}

A mixture of 4 different siRNA sequences specific to $K d m 6 a$ was used at a final concentration of $40 \mathrm{nM}$ total RNA during transfection (1: AGUUAGCAGUGGAACGUUA, 2: GGA CUUGCAGCACGAAUUA, 3: GGUACGGCCUACUGG AAUU, 4: CCACGUUGGUCAUACUAUA; ON-TARGETplus Mouse Kdm6a Set of 4 siRNA, Dharmacon, UK). A non-targeting siRNA sequence (ntRNA; Dharmacon) was used as control and co-transfection with pmaxGFP (Lonza, Switzerland) was performed in all cases for transfected neurons identification. The efficacy of siRNA targeting $K d m 6 a$ was assessed by electroporation of neurons using a 4D-Nucleofector X Unit and the corresponding P3 Primary Cell nucleofection kit (Lonza) according to the manufacturer's instructions, followed by qPCR for $K d m 6 a$ after $16 \mathrm{~h}$ of knockdown. The same experimental design was used to analyze the effect of $K d m 6 a$ knockdown on $N g n 3$ gene expression. The transfection efficacy by electroporation was $15 \%$, calculated as the percentage of GFP-expressing cells over total number. For morphometric analysis, neurons were transfected at 3 DIV with siRNA targeting $K d m 6 a$ or ntRNA 
Table 1 Primer sequences used for gene expression assays by qPCR

\begin{tabular}{|c|c|}
\hline Gene & $\begin{array}{l}\text { Forward sequence } 5^{\prime}-3^{\prime} \\
\text { Reverse sequence } 5^{\prime}-3^{\prime}\end{array}$ \\
\hline$C d k 5 r 1$ & $\begin{array}{l}\text { GATGCTGCAGATCAATGCCG } \\
\text { GGAGTCGCTTCTTGTCCTCC }\end{array}$ \\
\hline$D d x 3 x$ & $\begin{array}{l}\text { ACTGCACAAGGTGTCAATTCTG } \\
\text { TCCCAGTGGCATAGGCATTT }\end{array}$ \\
\hline Dll1 & $\begin{array}{l}\text { GCGACTGAGGTGTAAGATGGAA } \\
\text { TCTCAGCAGCATTCATCGGG }\end{array}$ \\
\hline Eif $2 s 3 x$ & $\begin{array}{l}\text { GGTGAGGGTGGAGTGACTCT } \\
\text { TTCCCATGAGCTACGTGACCA }\end{array}$ \\
\hline Hesl & $\begin{array}{l}\text { CCAGCCAGTGTCAACACGA } \\
\text { AATGCCGGGAGCTATCTTTCT }\end{array}$ \\
\hline Hes 5 & $\begin{array}{l}\text { GGAGAAAAACCGACTGCGGA } \\
\text { AGCTGCTCTATGCTGCTGTT }\end{array}$ \\
\hline$K d m 5 c$ & $\begin{array}{l}\text { AACCTTGTGCAGTGTAACACACG } \\
\text { GGTTCCGGATCAGGCTGTAG }\end{array}$ \\
\hline$K d m 6 a$ & $\begin{array}{l}\text { GCTGGAACAGCTGGAAAGTC } \\
\text { GAGTCAACTGTTGGCCCATT }\end{array}$ \\
\hline Mecp2 & $\begin{array}{l}\text { ACAGCGGCGCTCCATTATC } \\
\text { CCCAGTTACCGTGAAGTCAAAA }\end{array}$ \\
\hline Neurod1 & $\begin{array}{l}\text { CTGCGAGATCCCCATAGACAAC } \\
\text { CCTCTAATCGTGAAAGATGGCATT }\end{array}$ \\
\hline Neurod2 & $\begin{array}{l}\text { CCAGAGGCAGTTGGTAAGGG } \\
\text { GCGGAGATTCGTGTTAGGGT }\end{array}$ \\
\hline Notch1 & $\begin{array}{l}\text { ACAGTGCAACCCCCTGTATG } \\
\text { TCTAGGCCATCCCACTCACA }\end{array}$ \\
\hline Syp & $\begin{array}{l}\text { AGTACCCATTCAGGCTGCAC } \\
\text { CCGAGGAGGAGTAGTCACCA }\end{array}$ \\
\hline Usp $9 x$ & $\begin{array}{l}\text { TCGCCATATTGAGGCTG } \\
\text { TTGCATAACCGAGAGCTTGC }\end{array}$ \\
\hline Uty & $\begin{array}{l}\text { GAAAAGGCTAGAGGCGAGGG } \\
\text { AACCCGAAGAAGCTGCTATCTAA }\end{array}$ \\
\hline Rn18s & $\begin{array}{l}\text { CGCCGCTAGAGGTGAAATTCT } \\
\text { CATTCTTGGCAAATGCTTTCG }\end{array}$ \\
\hline
\end{tabular}

using Effectene Transfection Reagent (Qiagen, Germany) according to the manufacturer's instructions. After $16 \mathrm{~h}$ of knockdown, cultures were processed for axonal length measurement. The transfection efficacy by this method was $0.1 \%$.

\section{Western blot}

2 DIV hypothalamic neurons were treated with $0.5,1$, $1.8 \mu \mathrm{M}$ GSK-J4 (Sigma-Aldrich) or vehicle for $24 \mathrm{~h}$ and then washed, harvested at $4{ }^{\circ} \mathrm{C}$ in RIPA buffer with protease and phosphatase inhibitors, and proteins were resolved and transferred onto nitrocellulose membranes (GE Healthcare, UK) as previously described [44]. Membranes were blocked $90 \mathrm{~min}$ at room temperature (RT) in Tris-buffered saline containing $0.1 \%$ Tween 20 and 5\% BSA, and then incubated overnight at $4{ }^{\circ} \mathrm{C}$ with $1: 1000$ anti-H3K27me3 primary antibody (Cell Signaling Technology, USA). After that, membranes were incubated $1 \mathrm{~h}$ at RT with 1:10000 infrared dyeconjugated secondary antibody (LI-COR, USA) and proteins were visualized by Odyssey Infrared Imaging System (LICOR). After H3K27me3 visualization, blots were stripped and then re-probed with 1:2000 anti-total $\mathrm{H} 3$ primary antibody (Cell Signaling Technology) to ensure equal protein loading. Densitometric analyses were performed with the ImageJ software (National Institutes of Health; freely available at https://imagej.nih.gov). Data are presented as a ratio of H3K27me3/total H3 of 3-4 independent cultures.

\section{Immunocytochemistry}

After treatment, neurons were fixed for $20 \mathrm{~min}$ at RT in $4 \%$ paraformaldehyde prewarmed to $37^{\circ} \mathrm{C}$. Transfected neurons were rinsed and mounted on glass slides immediately after, while neurons treated with GSK-J4 were rinsed, permeabilized for 6 min with $0.12 \%$ Triton-X plus $0.12 \%$ gelatin in phosphate-buffered saline (PBS), blocked $1 \mathrm{~h}$ at RT in PBS/ gelatin, and incubated for $1 \mathrm{~h}$ at RT with anti-microtubule associated protein 2 (MAP2) mouse monoclonal antibody 
(diluted 1:200 in PBS/gelatin; Sigma-Aldrich) and with anti-Tau rabbit polyclonal antibody (diluted 1:500 in PBS/ gelatin; Abcam, UK). After rinsing with PBS, cells were incubated for $1 \mathrm{~h}$ at RT with the secondary antibodies Alexa 594 goat anti-mouse, for the detection of MAP2, and Alexa 488 goat anti-rabbit, for the detection of Tau (diluted 1:1000 in PBS/gelatin; Jackson ImmunoResearch, USA). Finally, neurons were mounted on glass slides using gerbatol $(0.3 \mathrm{~g} /$ $\mathrm{ml}$ glycerol, $0.13 \mathrm{~g} / \mathrm{ml}$ Mowiol, $0.2 \mathrm{M}$ Tris-HCl, $\mathrm{pH} 8.5$ ) plus 1:5000 DAPI for nuclei staining.

\section{Morphometric analysis}

Morphometric evaluation consisted of the assessment of neuritic arborization and axonal length, using in all cases digitized images of the immunostained neurons obtained at $20 \times$ magnification with a standard Leica DMI 6000 fluorescence microscope (Leica, Germany) equipped with a digital camera of the same firm. At 4 DIV, the minor processes/ dendrites were identified as MAP2 immunoreactive neurites with acute-angled branching, whereas the axon was recognized as a single, thinner neurite of homogeneous caliber along its entire length, at least three times longer than the other processes, with right-angled branching and Tau selective immunoreactivity. Evaluation of neuritic arborization was carried out by a Sholl analysis [45] performed with the CellTarget software ([46]; freely available at https://www3. uah.es/biologia_celular/JPM/CellTarget/CellTarget.html). A grid of 6 concentric circles with an increasing radius of $5 \mu \mathrm{m}$ one respect to the previous one was placed centered on the cell soma, and the number of times neurites intersected any circle was counted in 30 neurons per experimental condition and culture (4 independent cultures). The total number of intersections per neuron was obtained and neuritic arborization complexity was estimated by the Branching Index (BI; [46]). Axonal length was randomly measured in 50-80 neurons per experimental condition and culture (4 independent cultures) using the NeuronJ ImageJ plugin ([47]; freely available at https://imagescience.org/meijering/software/ neuronj/).

\section{Statistical analysis}

Data are presented as mean \pm SEM and were statistically evaluated by one-, two- or three-way analysis of variance (ANOVA) with treatment, gonadal sex and/or sex chromosome complement as independent variables. In two- and three-way ANOVAs, the statistical significance of the effects of each independent variable and their interactions was tested. Post hoc comparisons of means by Fisher's Least
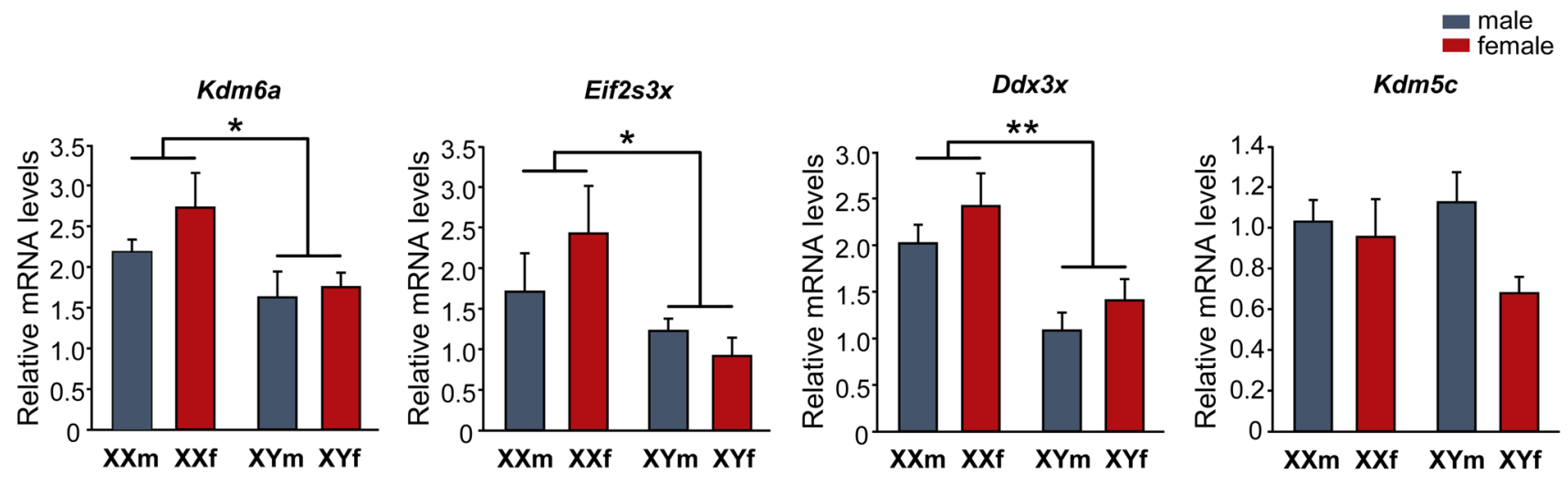

Mecp2

Usp9x

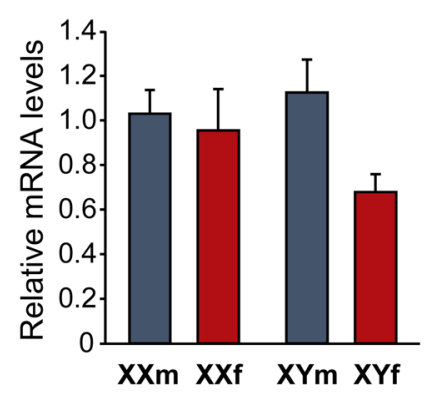

Syp
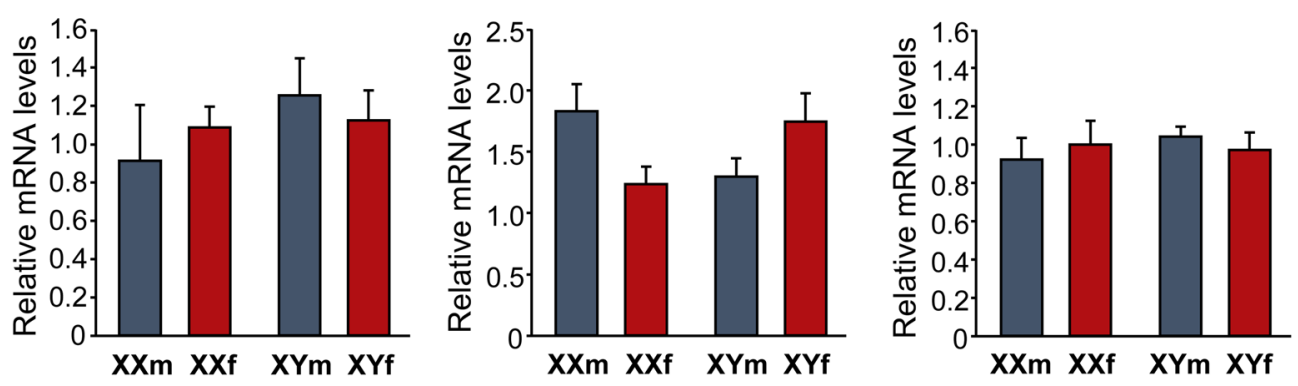

Fig. 1 Relative mRNA levels of X-linked genes Kdm6a, Eif2s3x, $D d x 3 x, K d m 5 c, M e c p 2$, Usp $9 x$, and Syp in FCG hypothalamic neurons at 3 DIV. Kdm6a, Eif $2 s 3 x$, and $D d x 3 x$ show higher expression levels in $\mathrm{XX}$ compared to $\mathrm{XY}$ cultures, regardless of gonadal sex (XXf and XXm $>$ XYf and XYm). Data are mean \pm SEM. $n=5-7$ independent cultures for each genotype. $* p<0.05$; $* p<0.01$ 
Significant Difference (LSD) test were performed for those variables/interactions for which ANOVA $p$ values were statistically significant. Statistical analysis was performed entirely with Statistica 8 software (StatSoft Inc., USA). $p<0.05$ was considered statistically significant. Sample size (n) for all experiments was 3-9 individuals/independent cultures and it is indicated in the figure legends. The number of independent cultures corresponds to the number of pregnant mothers or the number of embryos of each genotype and treatment for wild-type or FCG cultures, respectively. FCG embryos were obtained from 3-5 pregnant mothers per experiment.

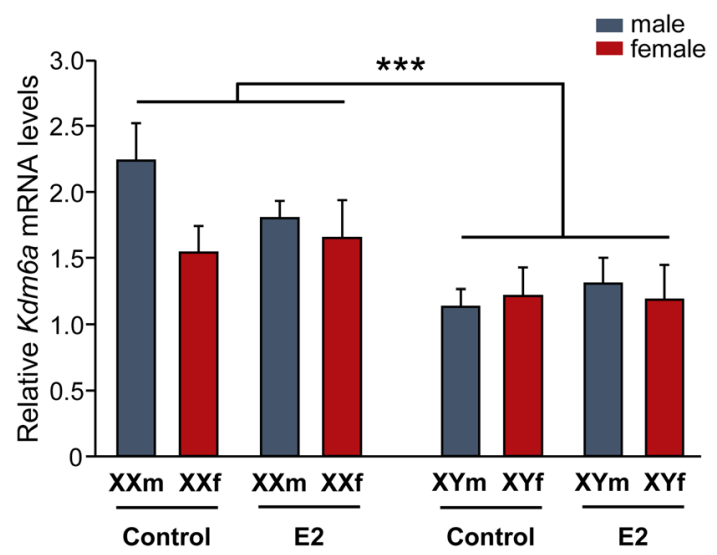

Fig. 2 17 $\beta$-estradiol (E2) effect on $K d m 6 a$ mRNA levels in FCG hypothalamic neurons. Incubation with $10^{-10}$ M E2 did not change Kdm6a gene expression levels, remaining higher in XX vs. $\mathrm{XY}$ cultures, regardless of sex and treatment. Data are mean \pm SEM. $n=4-5$ independent cultures for each genotype and treatment. $* * * p<0.001$

\section{Results}

\section{$K d m 6 a, D d x 3 x$, and Eif2s3x expression is higher in XX hypothalamic neurons regardless of gonadal sex}

First, we studied the expression of several X-linked genes particularly interesting for their involvement in neuronal growth and differentiation, to identify those with higher expression levels in XX than in XY neurons. Primary cultures of hypothalamic neurons from E14 FCG mice were established, maintained during $3 \mathrm{DIV}$, and then processed to determine the relative mRNA levels of seven X-linked genes by qPCR: $K d m 6 a, E i f 2 s 3 x, D d x 3 x, K d m 5 c, M e c p 2$, Usp $9 x$, and $S y p$ (Fig. 1). Two-way ANOVA revealed no effect of gonadal sex, but a significant main effect of sex chromosome complement in Kdm6a, Ddx $3 x$ and Eif2s $3 x$, presenting these genes significantly higher expression levels in hypothalamic neurons carrying the XX chromosome complement compared to those carrying the $X Y$, regardless of the gonadal sex of the donor embryos $(\mathrm{XX}>\mathrm{XY}$; Kdm6a: $\mathrm{F}(1,18)=6.58, p=0.0194 ; D d x 3 x$ : $\mathrm{F}(1,19)=14.14, p=0.0013$; Eif $2 s 3 x: \mathrm{F}(1,17)=5.79$, $p=0.0278)$. There was no interaction of gonadal sex and sex chromosome complement effects. On the other hand, no differences by either sex chromosome complement, or gonadal sex were found in $K d m 5 c, M e c p 2, U s p 9 x$, and Syp mRNA levels.

\section{Higher Kdm6a expression levels in XX neurons do not change with $E 2$ treatment or age}

Given the role of $K d m 6 a$ as a key epigenetic regulator of gene transcription and considering the results showing

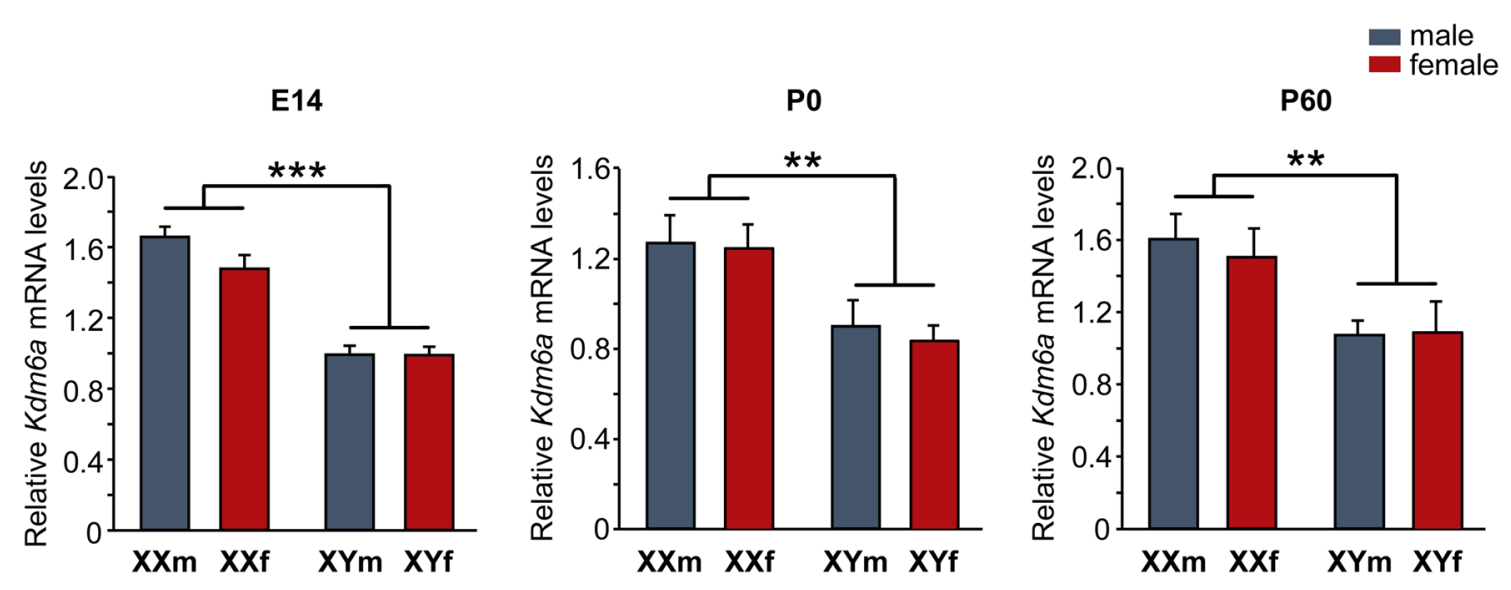

Fig. 3 Relative $K d m 6 a$ mRNA levels in hypothalamic tissue of FCG mice at E14, P0, and P60. Gene expression was higher in XX than $\mathrm{XY}$ animals at all ages and independently of gonadal sex. Data are mean \pm SEM. $n=5-6$ individuals for each genotype and age. $* * p<0.01 ; * * * p<0.001$ 
its sexually dimorphic expression determined by the sex chromosome complement (XX $>\mathrm{XY}$ ), we decided to focus our study henceforth on its involvement in the sex-specific differentiation of hypothalamic neurons. First, knowing the importance of E2 as the main sex hormone mediating organizational processes in the rodent brain, we treated cultures with this estrogen and analyzed the effect on $K d m 6 a$ mRNA levels. Remarkably, three-way ANOVA showed that E2 in the culture milieu did not alter Kdm6a gene expression levels, maintaining higher values in XX than in XY neurons, independently of gonadal sex and hormonal treatment (Fig. 2; $\mathrm{F}(1,28)=14.14, p=0.00079$ ).

Moreover, Kdm6a expression pattern did not change either with age, remaining higher in the hypothalamic tissue of XX than XY animals at E14 (two-way ANOVA: $\mathrm{F}(1,19)=87.74, p=0.000000015)$, postnatal day $0(\mathrm{P} 0$, newborns; two-way ANOVA: $\mathrm{F}(1,13)=12.49, p=0.0037$ ), and postnatal day 60 (P60, gonadally intact adults; two-way ANOVA: $\mathrm{F}(1,15)=11.15, p=0.0045)$, regardless of whether individuals carried testes or ovaries (Fig. 3).

\section{Kdm6 H3K27 demethylase activity is required for the differentiation of longer axons in XX hypothalamic neurons}

To analyze the requirement for Kdm6 H3K27 demethylase activity in the sexually dimorphic differentiation of hypothalamic neurons, we employed the specific cell-permeable small-molecule inhibitor GSK-J4 [48]. First, we validated the effectiveness of GSK-J4 blocking Kdm6 demethylase activity in primary cultures of hypothalamic neurons from wild-type CD1 mice, performing a dose/response curve and evaluating the H3K27me3 levels by Western blot. In agreement with times and concentrations previously reported by others [49], treatment of cultures for $24 \mathrm{~h}$ with GSK-J4 $1.8 \mu \mathrm{M}$ showed the highest H3K27me3 levels (Fig. 4a; oneway ANOVA: $\mathrm{F}(3,10)=10.45, p=0.002)$ without affecting cell viability, proving to be effective in inhibiting the Kdm6 enzymatic activity. Besides, treatment did not affect the gene expression levels of Kdm6a or its paralogue on the Y chromosome, Uty, presenting neuronal cultures derived from female embryos higher Kdm6a mRNA levels than those from male, both in control and treated conditions (Fig. 4b; two-way ANOVA: $\mathrm{F}(1,13)=10.25, p=0.007)$. Considering these results, we selected this condition for all further experiments using GSK-J4 to inhibit Kdm6 demethylase activity.

Thereafter, we evaluated the effect of Kdm6 H3K27 demethylase activity inhibition by GSK-J4 over neuronal growth and differentiation in vitro, analyzing neuritic arborization complexity and axonal length as parameters of neuronal morphology. Assessment of neuritic arborization was performed by a Sholl analysis, counting per cell the number of times neurites intersected any line of the concentric circle grid (Fig. 5a). At this level, significant differences were only observed in the number of intersections due to sex, with no effect of GSK-J4 or sex-treatment interaction: neurons derived from female embryos presented a higher mean number of intersections than those from male embryos, independently of GSK-J4 blockade (Fig. 5b; two-way ANOVA: F(1, $12)=5.15, p=0.0425$ ). Accordingly, calculation of the BI estimated a higher complexity in the neuritic arborization of female $(\mathrm{BI}=14.91 \pm 0.85)$ than male $(\mathrm{BI}=11.26 \pm 1.25)$

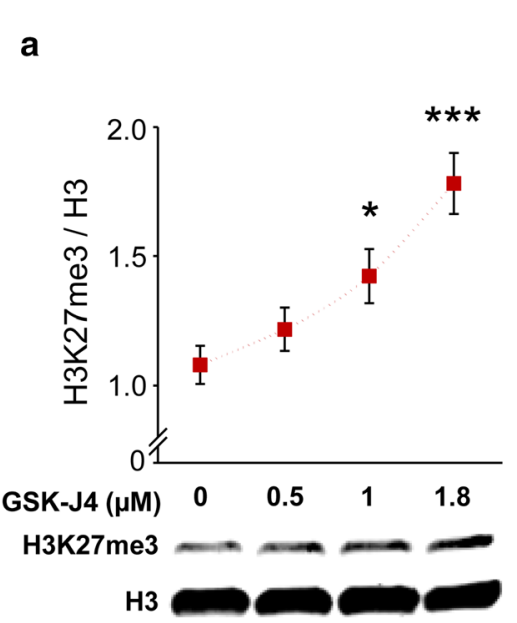

Fig. 4 Validation of GSK-J4 treatment as an inhibitor of Kdm6 demethylase activity in wild-type hypothalamic neurons. a Quantification and a representative immunoblot showing the increase in histone 3 lysine 27 trimethylation (H3K27me3) levels as a result of Kdm6 demethylation blockade for $24 \mathrm{~h}$ at increasing concentrations of GSK-J4. Total histone $3(\mathrm{H} 3)$ was used as a loading control. b GSK-J4 $1.8 \mu \mathrm{M}$ b
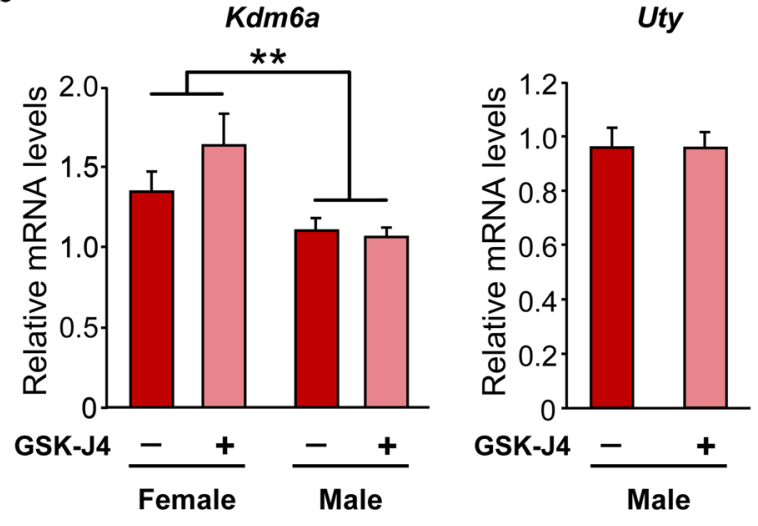

treatment for $24 \mathrm{~h}$ inhibited demethylation without affecting $K d m 6 a$ or Uty gene expression. Kdm6a mRNA levels were higher in female than male cultures, regardless of treatment. Data are mean \pm SEM. $n=3-6$ independent cultures for each sex and treatment. ${ }^{*} p<0.05$; $* * p<0.01 ; * * * p<0.001$ 

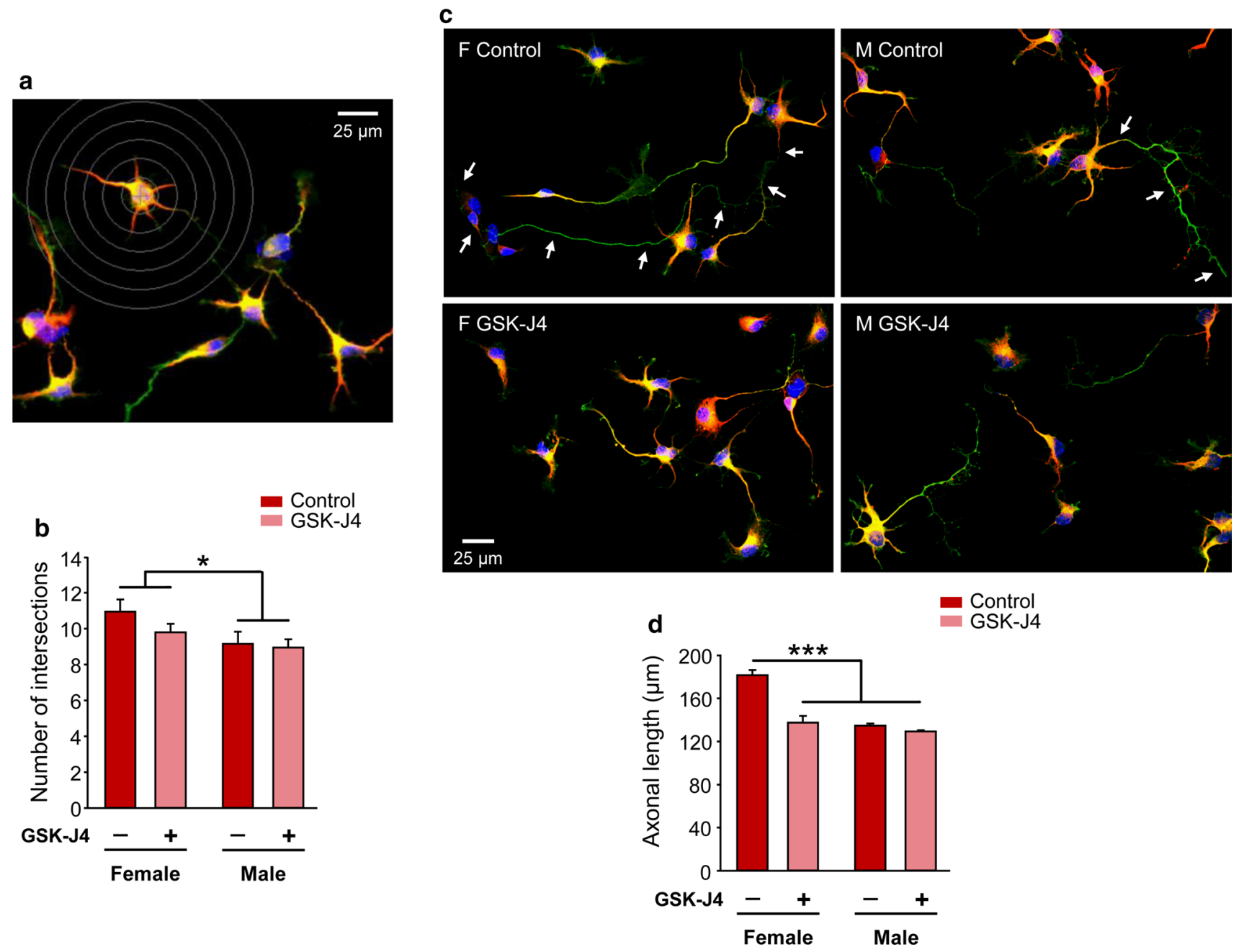

Fig. 5 Sexually dimorphic neuritogenesis of hypothalamic neurons depends on Kdm6 H3K27 demethylase activity. a Representative fluorescence image of female control neurons showing the grid used for Sholl analysis. b Number of intersections of neurites with Sholl's grid of female and male neurons treated (GSK-J4) or not (Control) at 3 DIV with GSK-J4 $1.8 \mu \mathrm{M}$ for $24 \mathrm{~h}$. Female neurons showed higher values than male neurons, irrespective of treatment. c Representative fluorescence images of female (F) and male (M) neu-

neurons (two-way ANOVA: $\mathrm{F}(1,12)=6.067, p=0.03$ ), without GSK-J4 treatment or sex-treatment interaction effects. Regarding axonal length analysis, in agreement with previous results $[34,35]$, a clear sexual dimorphism was observed in control conditions, showing female neurons significantly longer axons on average than male neurons. Remarkably, two-way ANOVA revealed a significant effect of sex-GSK-J4 interaction $(\mathrm{F}(1,12)=22.86, p=0.0004)$, with GSK-J4 treatment decreasing axonal length only in female derived neurons and thus nullifying the sex differences observed in control conditions (Fig. 5c, d).

rons treated (GSK-J4) or not (Control) at 3 DIV with GSK-J4 $1.8 \mu \mathrm{M}$ for $24 \mathrm{~h}$. Arrows indicate the axon of a female control neuron and a male control neuron along their full length. $\mathbf{d}$ Mean axonal length for each experimental condition. GSK-J4 treatment abolished sex differences decreasing axonal length only in female neurons. Data are mean \pm SEM. $n=4$ independent cultures for each sex and treatment. $* p<0.05 ; * * * p<0.001$

\section{Kdm6 H3K27 demethylase activity regulates the expression of $\mathrm{Ngn} 3$ in a sex-specific manner determined by the sex chromosome complement}

Since in previous work we have demonstrated that higher expression of $\mathrm{Ngn} 3$ in $\mathrm{XX}$ hypothalamic neurons is required for faster maturation and longer axons of these neurons in vitro [34], we investigated whether $K d m 6 a$ regulates the expression of $\mathrm{Ngn} 3$ and other neuritogenic genes such as Neurod1, Neurod2, and Cdk5r1. Cultures from E14 wildtype mice segregated by sex were maintained 2 DIV and then treated with GSK-J4 for $24 \mathrm{~h}$ before processing for gene expression analysis by qPCR. As in Scerbo et al. [34], 
a

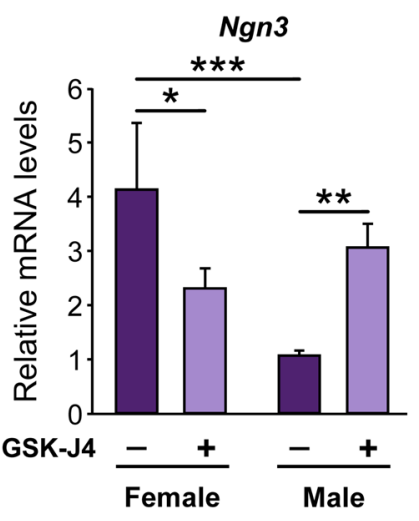

b

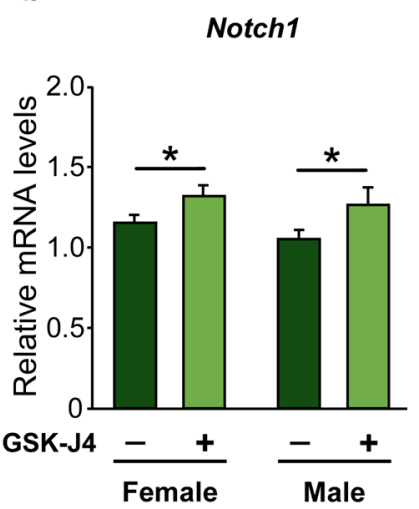

Neurod1

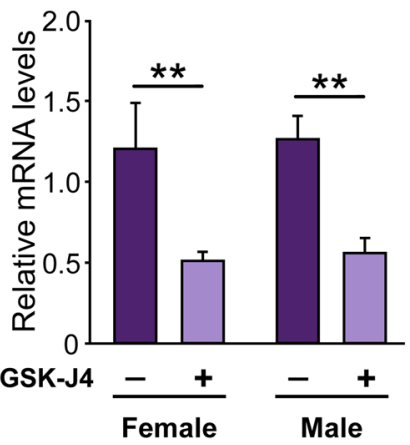

DII1

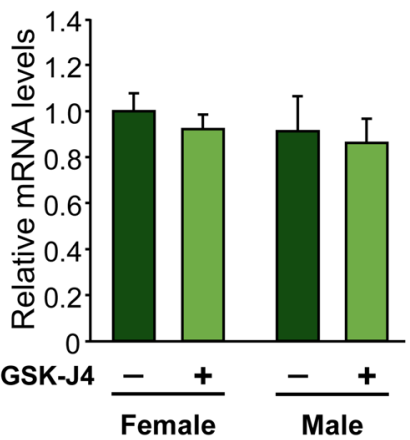

Fig. 6 Effect of Kdm6 H3K27 demethylase activity inhibition on neuritogenesis-related genes expression in wild-type hypothalamic neurons. a Effect of GSK-J4 treatment on neuritogenic genes expression. Kdm6 demethylases blockade reduced Neurod1, Neurod 2 and Cdk5rl mRNA levels in both sexes equally, while a sex-specific effect was observed on Ngn3 levels, with a decrease in female and

neurons derived from female embryos presented higher Ngn3 mRNA levels than those from males under control conditions. Interestingly, inhibition of Kdm6 demethylase activity significantly reduced $\mathrm{Ngn3}$ expression in female cultures, while increasing it in males (Fig. 6a; two-way ANOVA, sex-GSK-J4 interaction effect: $\mathrm{F}(1,24)=14.75$, $p=0.0008)$. Moreover, GSK-J4 treatment significantly reduced Neurod1, Neurod2, and Cdk5rl gene expression equally in both sexes (Fig. 6a; two-way ANOVA, GSK-J4 treatment main effect: Neurod1: $\mathrm{F}(1,25)=13.5, p=0.001$; Neurod2: $\mathrm{F}(1,24)=10.15, p=0.0039 ;$ Cdk5rl: $\mathrm{F}(1$, 18) $=4.41, p=0.049)$.

Next, we evaluated the effect of the Kdm6 demethylase activity inhibition over the expression of some of the main Notch signaling elements, knowing that Ngn3 transcription is downregulated when this pathway is activated [50, 51]. Statistical analysis showed no significant differences due to gonadal sex, GSK-J4 treatment or sex-treatment interaction
Neurod2

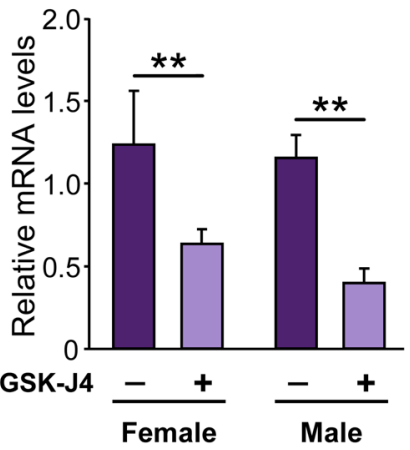

Hes1
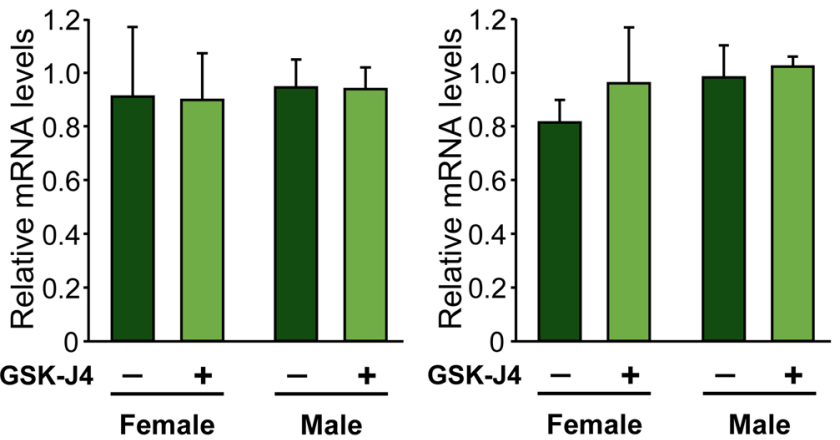

an increase in male neurons. b Effect of GSK-J4 treatment on Notch signaling genes expression. Kdm6 demethylases blockade did not change Dll1, Hes 1, and Hes 5 mRNA levels, while Notch1 expression increased with treatment both in female and male neurons. Data are mean \pm SEM. $n=4-9$ independent cultures for each sex and treatment. $* p<0.05$; ** $p<0.01 ; * * * p<0.001$

in Dll1, Hes 1, and Hes 5 relative mRNA levels, while Notch1 expression increased with treatment both in female and male neurons (Fig. 6b; two-way ANOVA: F(1, 18)=5.68, $p=0.028)$.

Finally, neuronal cultures derived from FCG transgenic mice were treated with the GSK-J4 inhibitor and processed for Ngn3 relative expression analysis. Three-way ANOVA indicated a significant effect of sex chromosome complement-GSK-J4 interaction $(\mathrm{F}(1,21)=29.646, p=0.00002)$, with inhibition of Kdm6 H3K27 demethylase activity by GSK-J4 inducing a decrease in Ngn3 levels in XX neurons and an increase in XY neurons, in line with the results observed in wild-type cultures and irrespective of gonadal type (Fig. 7). 


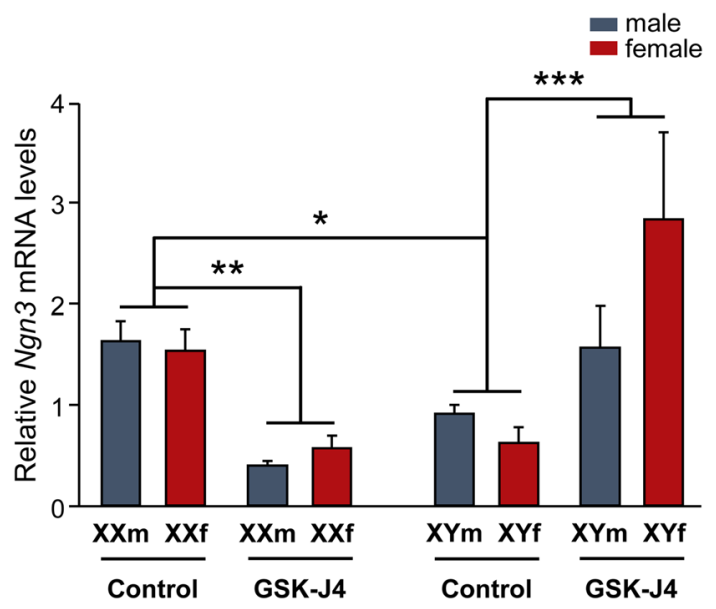

Fig. 7 Kdm6 H3K27 demethylation regulates Ngn3 expression in a sex-specific manner determined by the sex chromosome complement. In control conditions, FCG XX hypothalamic neurons express higher Ngn3 mRNA levels than XY neurons, regardless of gonadal sex. Kdm6 demethylases blockade by GSK-J4 generated a decrease in Ngn3 mRNA levels in XX and an increase in XY neurons. Data are mean \pm SEM. $n=3-5$ independent cultures for each genotype and treatment. $* p<0.05 ; * * p<0.01 ; * * * p<0.001$

\section{$K d m 6 a$ is specifically required for the expression of higher levels of $\mathrm{Ngn} 3$ and the differentiation of longer axons in XX hypothalamic neurons}

Given the results that suggest a participation of Kdm6 enzymes in the sexually dimorphic regulation of axogenesis and $\mathrm{Ngn3}$ expression in hypothalamic neurons, and that treatment with GSK-J4 inhibits the activity of both Kdm6a and Kdm6b, being impossible by this methodological approach to discern the individual contribution of each demethylase, we proceeded to the specific knockdown of $K d m 6 a$ transcripts using siRNA designed to downregulate the expression of this gene without affecting $K d m 6 b$ or $U t y$. Once the effectiveness of siRNA decreasing Kdm6a mRNA levels was proven (Fig. 8a; oneway ANOVA: $\mathrm{F}(1,21)=22.09, p=0.00012)$, neuronal cultures derived from sex-segregated wild-type mice were transfected to study the effect of $\mathrm{Kdm} 6 \mathrm{a}$ knockdown on $\mathrm{Ngn} 3$ expression and axonal growth. Again, as in the pharmacological approach using GSK-J4, morphometric analysis showed a significant reduction in axonal elongation in female but not in male derived neurons after $K d m 6 a$ downregulation, abolishing the sex differences observed in axonal length in control conditions (Fig. 8c, d; two-way ANOVA, sex-siRNA interaction effect: $\mathrm{F}(1,9)=6.16, p=0.0348)$. Interestingly, and in accordance with the results regarding axogenesis, $K d m 6 a$ specific knockdown produced a decrease in Ngn3 mRNA levels only in female derived neurons without affecting the expression of the gene in male cultures (Fig. 8b; two-way ANOVA, sex-siRNA interaction effect: $\mathrm{F}(1,10)=6.17, p=0.0323$ ).

\section{Discussion}

Currently, it is well known that the sex chromosome complement contribution to brain sexual differentiation is not just limited to the determination of a gonadal type in utero (testes for $\mathrm{XY}$, ovaries for $\mathrm{XX}$ ), but continues playing a role in the development and expression of sex dimorphisms at morphological, physiological, and behavioral levels throughout life. However, little is known about the identity of particular $\mathrm{X}$ or Y-linked genes involved and the mechanisms by which these genes participate in the process. Here we provide valuable evidence pointing to $K d m 6 a$ as one of the main X-linked mediators of the sexually dimorphic differentiation of hypothalamic neurons, regulating sex differences in the expression of the proneural gene Ngn3 and axonal growth. These evidences contribute to the understanding of the elements and mechanisms that govern the sex-specific differentiation of the ventromedial hypothalamus (VMH), a brain region pivotal in the control of homeostasis and reproduction and known to be a highly sexually dimorphic structure $[2,52$, 53].

Although the $\mathrm{X}$ chromosome comprises only about $5 \%$ of the mouse and human genomes, it is particularly enriched in brain-relevant genes, containing five times as many genes linked to the development and physiology of the nervous system compared to an autosome [6, 54-56]. Many of these genes escape XCI, although expression levels from the Xi vary between escapees and can be tissue-, developmental stage-, species-, individual-, and even single cell-dependent for the same gene $[15,57,58]$. Among the seven X-linked genes whose relative expression we analyzed by qPCR, all show previous evidence of XCI escape in different tissues in both mice and humans with the exception of Mecp2 [59-64]. Our results show that while $K d m 6 a$, Eif $2 s 3 x$, and $D d x 3 x$ presented higher expression levels in $\mathrm{XX}$ compared to $\mathrm{XY}$ hypothalamic neurons and independently of gonadal sex, $K d m 5 c, M e c p 2, U s p 9 x$, and Syp did not vary in expression among the four genotypes in the FCG model. In the mouse nervous system, $K d m 6 a, K d m 5 c$, Eif $2 s 3 x$, and $D d x 3 x$ have been shown to escape XCI in studies using whole brain [14, $61,65,66]$, while few studies have assessed this question specifically by brain region and cell type. Armoskus et al. [67] demonstrated, by mRNA extraction from tissue blocks encompassing the cerebral cortex and hippocampus of neonatal mice, a higher expression of Kdm6a and Eif $2 s 3 x$ in females compared to males. On the other hand, $\mathrm{Xu}$ et al. [68] have reported higher levels of Kdm6a mRNA in adult females in cortex, striatum, suprachiasmatic nucleus, $\mathrm{VMH}$, hippocampus (CA1/CA3), dentate gyrus, and habenula. In turn, the same study demonstrated that this dimorphism is sex chromosome complement dependent, as higher $K d m 6 a$ expression was observed in the whole brain of adult XX 

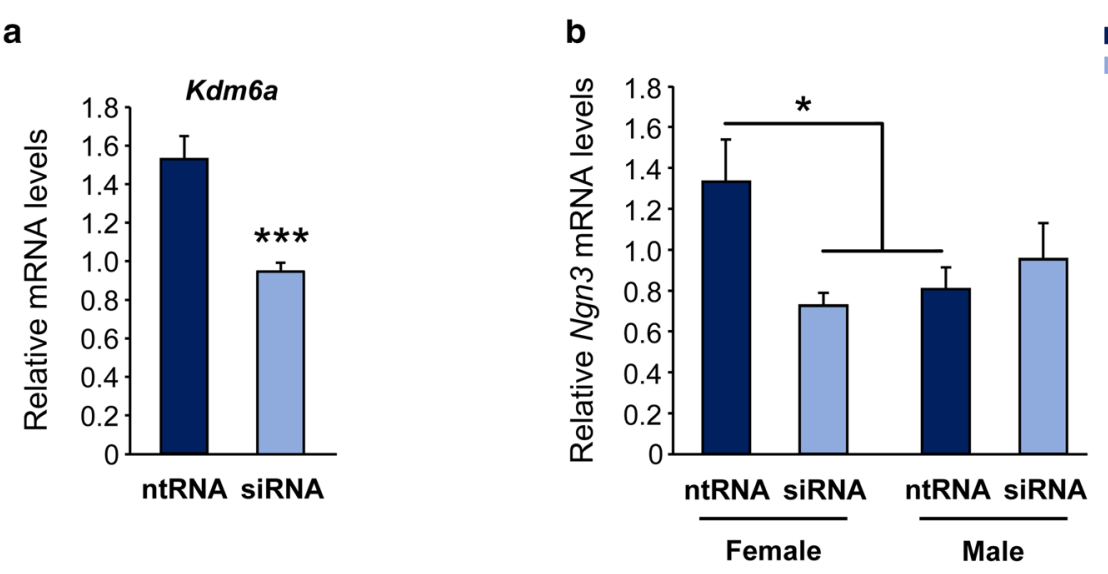

c
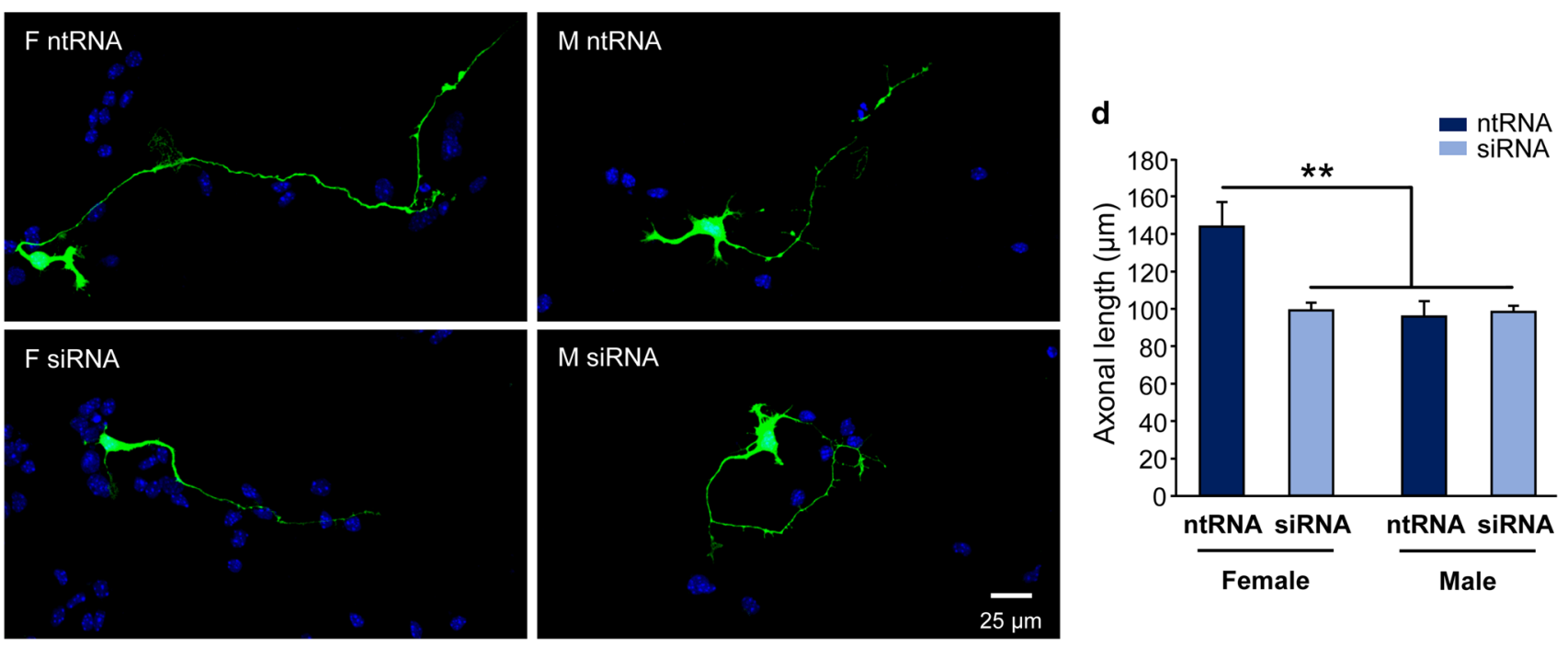

Fig. 8 Higher Kdm6a gene expression is required for Ngn3 higher levels and differentiation of longer axons in female hypothalamic neurons. a siRNA targeting Kdm6a (siRNA) were effective downregulating the demethylase mRNA levels in hypothalamic neurons in vitro. A non-targeting siRNA sequence (ntRNA) was used as a control. b $K d m 6 a$ knockdown eliminated sex differences in Ngn3 gene expression by downregulating the proneural gene only in female derived neurons. c Representative fluorescence images of female (F) and male (M) neurons co-transfected with ntRNA and GFP or siRNA targeting $K d m 6 a$ and GFP at 3 DIV for $16 \mathrm{~h}$. d Mean axonal length for each experimental condition. Kdm6a knockdown abolished sex differences decreasing axonal length only in female neurons. Data are mean \pm SEM. $n=4-7$ independent cultures for each sex and treatment. $* p<0.05 ; * p<0.01 ; * * * p<0.001$
FCG mice (both gonadal males and females) compared to $\mathrm{XY}$ mice. As far as we are aware, the present is the first study to explore and demonstrate the sexually dimorphic expression of $K d m 6 a$, Eif $2 s 3 x$, and $D d x 3 x$ specifically in hypothalamic neurons prior to the organizational action of gonadal hormones. The use of the FCG transgenic model and the election of a developmental time prior to the critical period of brain hormonal organization allows us to present robust results clearly showing that the sexually dimorphic expression of Kdm6a, Eif2s $3 x$, and $D d x 3 x$ is determined by the sex chromosome complement $(\mathrm{XX}>\mathrm{XY})$, and strongly suggesting that these genes escape XCI in hypothalamic neurons during early development.
Considering the sex differences in Kdm6a, Eif2s $3 x$, and $D d x 3 x$ expression and their regulatory functions either at the transcriptional or translational level, it is possible to hypothesize that these genes could be involved in the definition of sexual dimorphisms during brain development. $D d x 3 x$ encodes for an evolutionarily conserved DEAD-box RNA helicase involved in a multiplicity of fundamental cellular processes, including transcription, splicing, mRNA transport, translation, and regulation of the $\mathrm{Wnt} / \beta$-catenin signaling pathway [69-71]; mutations in this gene have been reported in different types of cancer and associated with intellectual disability [72]. On the other hand, little is known about the functions of Eif2s $3 x$ beyond the fact that it is involved in the regulation of protein synthesis as a subunit 
of the translation initiation factor eIF2 [73, 74]. Finally, particularly interesting is $K d m 6 a$, which protein product plays important roles as a genome-wide regulator of gene expression not only by removing $\mathrm{H} 3 \mathrm{~K} 27 \mathrm{me} 2 / \mathrm{me} 3$ repressive marks but also by directly interacting with promoter regions [19, 20]. Since $D d x 3 x$ and Eif2s $3 x$ activity is almost exclusively post-transcriptional and that our immediate background showed sex chromosome complement control over autosomal genes at a transcriptional level, we decided to focus on $K d m 6 a$. Thus, considering the key role of $K d m 6 a$ as an epigenetic regulator of transcription and its higher expression in XX hypothalamic neurons, we set out to further study its participation in the sexually dimorphic differentiation of these neurons.

In rodents, E2 converted from testosterone by the enzyme P-450 aromatase is by far the main steroid hormone responsible for brain masculinization and defeminization during the so-called critical or sensitive period of sexual differentiation, which comprises the E17-P10 perinatal phase of development $[42,75]$. Surprisingly, no significant differences in Kdm6a mRNA levels were found between E2-treated and unstimulated control cultures, always observing higher $K d m 6 a$ levels in $\mathrm{XX}$ neurons, irrespective of sex and treatment. Many estrogen actions depend on mediation or interaction with other trophic factors, such as neurotrophins (BDNF, IGF-I, GDNF), neurotransmitters (GABA, glutamate), and many other regulatory molecules (prostaglandins, neuroglobin, huntingtin, etc.), often produced and secreted by cells other than neurons, as is the case with glial cells in nervous tissue [75-80]. For such reason we decided to validate in vivo what was observed in primary cultures, evaluating in tissue from the hypothalamic region whether the expression pattern of $K d m 6 a$ changes depending on the sexually dimorphic fluctuations in circulating levels of gonadal hormones that occur throughout life. Consistent with the results from in vitro stimulation with E2, the higher $K d m 6 a$ expression in $\mathrm{XX}$ individuals and independent of gonadal sex remained unaltered in the hypothalamus at E14, P0, and P60 (before, during, and after the critical period, respectively), reinforcing evidence that the sex-specific expression pattern of the demethylase is directly determined by the number of $\mathrm{X}$ chromosomes present in each cell and would not be modulated by gonadal hormones.

Our laboratory has previously demonstrated and reported a sexual dimorphism in hypothalamic neurons differentiation prior to the action of gonadal hormones and dependent on sex chromosome complement during brain development: XX neurons show an accelerated neuritic development in vitro compared to $X Y$ neurons, in terms of axonal length and dendrite development and branching [34, 35]. For example, at 2 DIV cultures, it was observed that while $14 \%$ of the female neurons had reached stage III of in vitro development (polarized neurons), none of the male neurons had developed axon yet. In addition, female cultures showed a higher proportion of cells with branched neurites than male cultures. Interestingly, these sexual differences disappear under E2 stimulation, as only XY neurons respond to the estrogen by accelerating their development, elongating their axons in a clear axogenic effect, and matching XX neurons, suggesting that a similar effect could occur in vivo with the arrival of early gonadal secretions and their organizing actions on the brain during perinatal male development $[34,35,80$, 81]. Reisert et al. [82] and Ruiz-Palmero et al. [83] have reported similar results by observing that neuritic development initially occurs faster in female than in male cultures of rat diencephalon dopaminergic neurons and mouse hippocampal neurons, respectively.

The results of the present study showed that both the silencing of $K d m 6 a$ gene expression and the pharmacological blockade of its enzymatic activity affected axonal elongation only in female cultures, generating a decrease in axonal length that was not observed in male cultures. The GSK-J4 prodrug is hydrolyzed inside the cell to GSK-J1, this molecule being the active drug that inhibits H3K27 demethylase activity of the enzyme through competition for the 2-oxoglutarate co-substrate binding site [48]. GSK-J1 has been shown to be able to block the active site and inhibit the demethylase activity of all enzymes of the Kdm6 subfamily, i.e., Kdm6a, Kdm6b and Uty/Kdm6c (although in vivo demethylation capacity of the latter is under discussion; [84, 85]). Therefore, the results derived from GSK-J4 treatment of neuronal cultures could be reflecting the effects not only of blocking the demethylase activity of Kdm6a, but also that of the other Kdm6 enzymes. However, the same results were obtained when silencing $K d m 6 a$ gene expression by siRNA sequences designed to specifically degrade the transcripts of this demethylase without affecting Kdm6b and Uty. Taken together, the results obtained from both pharmacological blockade by GSK-J4 and Kdm6a silencing indicate that early sex differences in axogenesis of hypothalamic neurons depend in part on the sexually dimorphic expression of Kdm6a: its H3K27 demethylase activity and increased transcription in XX neurons are necessary for mediating the processes leading to the proper development of these cells, whereas they are not indispensable (at least at this time) for $\mathrm{XY}$ neurons. These observations become even more relevant considering previous work by other groups in which, for example, it was shown that while $K d m 6 a$ knockout (KO) is fatal in female mice at E11-12 (with severe heart malformations and defects in neural tube closure), KO males (albeit at a lower frequency than expected) survive to adulthood and are fertile $[84,86]$.

Previous studies have demonstrated a requirement for $K d m 6 a$ during neuronal development, for example, in the determination and differentiation of cortical neurons [23] and in the dendritic development, synapse formation and 
maturation, and synaptic transmission of mouse hippocampal neurons [27] and human neurons [28]. However, the precise mechanisms through which $K d m 6 a$ participates in these processes are unknown, although it is assumed to occur through the control of the expression profile of numerous genes directly involved in such processes. Several studies have demonstrated large-scale changes in the transcriptome following deletion or blockade of $K d m 6 a$, observing a significant decrease in the expression of genes linked to neurodevelopment, neurogenesis, synaptogenesis, and neurotransmitter transport and secretion, among other relevant neuronal processes [24, 27, 28, 87]. Ngn3 is a transcription factor with regulatory functions in nervous system development [88-90]. In the VMH, Ngn3 is essential in the specification of different neuronal subtypes, promoting the determination of neuronal groups expressing pro-opiomelanocortin (POMC) and steroidogenic factor 1 (SF1) and repressing the determination of neurons producing neuropeptide $\mathrm{Y}$ and tyrosine hydroxylase [91]. In Scerbo et al. [34], our laboratory demonstrated that, prior to the critical period, hypothalamic neurons derived from female embryos exhibit higher levels of the neuritogenic factor Ngn3 than male neurons. In turn, it was observed that the higher expression of $N g n 3$ is necessary for the more accelerated development shown by female hypothalamic neurons in vitro. On the other hand, although it was shown in cultures derived from FCG transgenic mice that sexually dimorphic expression of $\mathrm{Ngn} 3$ is determined by the sex chromosome complement, the precise factors and mechanisms by which the $\mathrm{X}$ and $\mathrm{Y}$ chromosomes would regulate the expression of this autosomal gene are still unknown [34, 35]. Thus, knowing that both Kdm6a and Ngn3 participate in the regulation of sexually dimorphic neuritogenic development of hypothalamic neurons, that both genes show similar expression patterns with higher levels in XX than in XY neurons, and that Ngn3 expression is determined by the sex chromosome complement, we wondered whether Kdm6a would be responsible, at least in part, for controlling the sexually dimorphic expression of this proneural factor. The inhibition of H3K27 demethylation activity of Kdm6 by GSK-J4 generated similar results in cultures from wild-type and FCG transgenic animals in terms of $N g n 3$ expression: drug treatment decreased $N g n 3$ levels in XX hypothalamic neurons, whereas increasing them in $\mathrm{XY}$ neurons. These results suggest that $\mathrm{Ngn} 3$ expression is mediated by H3K27 demethylation, and indicate different regulatory mechanisms for males and females that are sex chromosome complement-dependent and gonadal sex-independent. Since Notch signaling pathway activation inhibits neurogenesis through repression of numerous proneural genes including $N g n 3$ [50,51], we decided to evaluate the effect of blocking H3K27 demethylation on gene expression of some of the main elements of this pathway. Results were equal in both sexes and showed an increase of Notchl after
GSK-J4 inhibition and no treatment effect on Dll1, Hes 1, and Hes 5 levels, suggesting that the sexually dimorphic regulation of Kdm6 demethylase activity on $\mathrm{Ngn} 3$ would not be mediated by the Notch pathway in hypothalamic neurons. Results from the use of siRNA targeting $K d m 6 a$ showed a significant decrease in Ngn3 mRNA levels only in female neurons without affecting male neurons, consistent with the effects observed in axogenesis. These results clearly demonstrate that the higher $K d m 6 a$ levels in XX hypothalamic neurons are necessary to induce the increased Ngn3 levels and axogenesis observed in these neurons prior to the critical period of brain hormonal organization, and suggest that the increase in Ngn3 expression in XY neurons following GSK$\mathrm{J} 4$ treatment is a complex and combinatorial effect generated by the global inhibition of the demethylation activity not only of Kdm6a but also of Kdm6b and Uty.

Taken together, our results point to $K d m 6 a$ as an X-linked gene directly involved in the sexually dimorphic differentiation of XX hypothalamic neurons, expressing at higher levels in these cells independently of gonadal sex, promoting through its H3K27 demethylase activity the transcription of Ngn3 and other proneural factors such as Neurodl, Neurod2, and $C d k 5 r l$, and mediating the process of axogenesis in a sex-specific manner prior to the hormonal organization of the brain. We have shown that the sex difference in $K d m 6 a$ transcriptional levels is determined by the sex chromosome complement, while gene expression results from E2-stimulated neuronal cultures and hypothalamus of neonatal and adult FCG animals strongly suggest that $K d m 6 a$ expression is not subject to sex hormone regulation per se. However, we cannot exclude the possibility that the sex-specific effects determined by Kdm6a on Ngn3 expression and axogenesis are mediated by sex steroids, for example, if they occur through a differential regulation of the demethylase on neurosteroidogenesis in XX and XY individuals. In this regard, it would be particularly interesting to develop further experiments focused on the possible involvement of $K d m 6 a$ in the regulation of the neurosteroidogenic pathway and the generation of sexual dimorphisms in the hypothalamus and other brain regions by this way.

Considering the results of the present study and our own and other groups' previous evidence, we propose the following hypothesis to explain the factors and mechanisms currently known to act in the sexual differentiation of hypothalamic neurons (Fig. 9). On the one hand, XX neurons, whose embryonic and perinatal development occurs in the absence of significant levels of gonadal hormones, show higher expression of X-linked genes that escape XCI, such as $K d m 6 a, D d x 3 x$, and Eif2s $3 x$. Greater Kdm6a levels (and possibly other $\mathrm{X}$-linked genes) during early neurodevelopment in XX neurons lead to increased expression of neuritogenic genes such as Ngn3, which, in turn, promotes neuritogenesis. On the other hand, XY neurons exhibit lower 


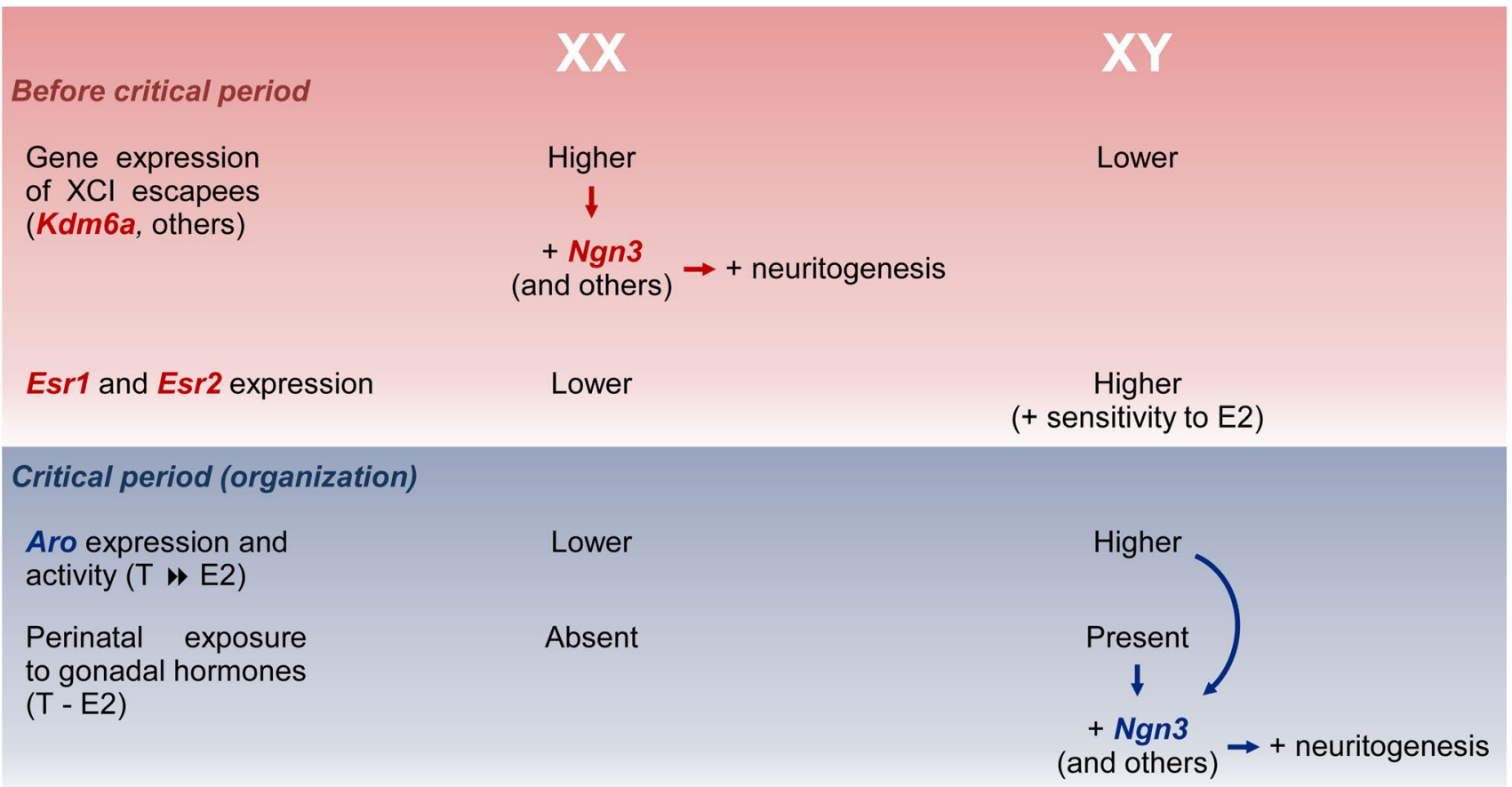

Fig. 9 Summary of the hypothesis proposed to explain the sexually dimorphic factors and mechanisms that act in the sexual differentiation of hypothalamic neurons. Before critical period of hormonal organization of the brain, $\mathrm{XX}$ neurons show higher expression of $\mathrm{X}$-linked genes that escape $\mathrm{X}$ chromosome inactivation (XCI) than $\mathrm{XY}$ neurons, such as $K d m 6 a, D d x 3 x$, and Eif2s $3 x$. Higher Kdm6a levels in XX neurons upregulate neuritogenic genes such as $\mathrm{Ngn3}$, Neurodl, Neurod2, and $C d k 5 r 1$ which, in turn, promotes neuritogenesis.

expression of neuritogenic-related escapee genes. However, these cells are influenced by E2 produced intraneuronally from testosterone secreted by testes during the critical period of perinatal development, presenting, in addition, a higher expression and enzymatic activity of aromatase [92, 93] and a higher sensitivity to $\mathrm{E} 2$ than $\mathrm{XX}$ neurons by expressing more estrogen receptors Esrl and Esr2 [35, 94]. E2 organizational actions during the critical period in XY neurons would ensure the increase in $\mathrm{Ngn} 3$ expression necessary for the promotion of neuritogenesis. Therefore, in terms of the neuritic development of hypothalamic neurons, different mechanisms would exist depending on the sex chromosome complement to ultimately determine the adequate neuritic arborization and axonal length in both sexes. Thus, dimorphic factors such as, for example, the higher expression of $\mathrm{X}$-linked genes in $\mathrm{XX}$ neurons or the early influence of gonadal hormones in $\mathrm{XY}$ neurons are compensated or balanced. In this way, starting from a different genetic background, through sexually dimorphic mechanisms, a similar neuritic development is reached in both sexes. Following this line of reasoning, evolution would have operated here by favoring the compensation of sexually dimorphic mechanisms that ultimately guarantees an adequate neuritic
During the critical period, XY neurons are exposed to the effects of estradiol (E2) converted intraneuronally from testosterone (T) by aromatase (Aro), presenting, in addition, a higher expression and activity of this enzyme and a higher sensitivity to E2 than XX neurons by expressing more estrogen receptors $E s r 1$ and Esr2. E2 organizational actions ensure the increase in $\mathrm{Ngn} 3$ expression necessary for the promotion of neuritogenesis in XY neurons

development of hypothalamic neurons in both males and females. The fundamental contribution of this study is the identification of the X-linked gene $K d m 6 a$ as an orchestrator of the sexually dimorphic maturation of hypothalamic neurons previously to gonadal hormones exposition. Since $\mathrm{Ngn} 3$ promotes the development of $\mathrm{SF}^{+}$and $\mathrm{POMC}^{+}$neurons in the $\mathrm{VMH}$ [91], and given the role of Kdm6a regulating Ngn3 expression, these results suggest that an X-linked gene might participate in the generation of different neuronal populations in the $\mathrm{VMH}$, a nucleus controlling food intake, sexual development, and reproduction. Future basic and clinical studies should take these sex-specific mechanisms into account when analyzing the development of hypothalamus. A thorough understanding of the molecular and cellular mechanisms that govern early sexual differentiation of the brain will lead to improve our understanding of sex-specific phenotypes in health and disease, allowing us to efficiently address pathologies of embryonic origin that show a clear sex divergence in their manifestations.

Author contributions LECZ and MJC conceived and designed the research. LECZ, CDC, and CS performed all experiments and analyzed 
data. LECZ, CDC, CS, MAA, LMGS, and MJC interpreted the results of the experiments. LECZ elaborated figures and wrote the first draft of the manuscript. MJC and MAA edited and revised the manuscript with critical input from all authors. All authors read and approved the final manuscript. MJC drafted the manuscript.

Funding Open Access funding provided thanks to the CRUE-CSIC agreement with Springer Nature. This study was supported by grants from Argentina: Consejo Nacional de Investigaciones Científicas y Técnicas (CONICET, PUE 2016 No. 22920160100135CO), Agencia Nacional de Promoción Científica y Tecnológica (ANPCyT, PICT 2015 No. 1333 and PICT 2019 No. 2176), and Secretaría de Ciencia y Tecnología de la Universidad Nacional de Córdoba (SECyT-UNC, 20182021) to MJC, from Spain: Agencia Estatal de Investigacion (AEI) co-funded by FEDER (BFU2017-82754-R and PID2020-115019RBI00) to MAA and LMGS and the Enhancing Mobility between Latin America, Caribbean and the European Union in Health \& Environment (EMHE)-CSIC Program (MHE-200057) to LMGS and MJC, and from international organizations: International Brain Research Organization (IBRO) Return Home Fellowship and International Society for Neurochemistry (ISN) and Committee for Aid and Education in Neurochemistry (CAEN) Grant to CDC. We would like to thank CSIC and the EMHE Program, Secretaría General Iberoamericana (SEGIB) and Fundación Carolina, and IBRO Latin America Regional Committee (LARC) Exchange Fellowship for financially supporting the research stays of LECZ at the Instituto Cajal, Madrid, Spain.

Availability of data and material The datasets generated and/or analyzed during the current study are available from the corresponding author on reasonable request.

Code availability Not applicable.

\section{Declarations}

Conflict of interest The authors declare that they have no conflict of interest.

Ethical approval All experimental procedures with animals were approved and controlled by the Institutional Animal Care and Use Committee (CICUAL) of the Instituto M. y M. Ferreyra, following national and international regulations, and were in accordance with the Consejería del Medio Ambiente y Territorio (Comunidad de Madrid, Ref. PROEX 200/14), the European Commission (86/609/CEE and 2010/63/UE), and the Spanish Government Directive (R.D.1201/2005) guidelines.

Consent to participate Not applicable.

Consent for publication Not applicable.

Open Access This article is licensed under a Creative Commons Attribution 4.0 International License, which permits use, sharing, adaptation, distribution and reproduction in any medium or format, as long as you give appropriate credit to the original author(s) and the source, provide a link to the Creative Commons licence, and indicate if changes were made. The images or other third party material in this article are included in the article's Creative Commons licence, unless indicated otherwise in a credit line to the material. If material is not included in the article's Creative Commons licence and your intended use is not permitted by statutory regulation or exceeds the permitted use, you will need to obtain permission directly from the copyright holder. To view a copy of this licence, visit http://creativecommons.org/licenses/by/4.0/.

\section{References}

1. Bao AM, Swaab DF (2011) Sexual differentiation of the human brain: relation to gender identity, sexual orientation and neuropsychiatric disorders. Front Neuroendocrinol 32(2):214-226. https:// doi.org/10.1016/j.yfrne.2011.02.007

2. Pfaff DW, Christen Y (2013) Multiple origins of sex differences in brain: neuroendocrine functions and their pathologies. Springer, New York

3. Cox KH, Rissman EF (2011) Sex differences in juvenile mouse social behavior are influenced by sex chromosomes and social context. Genes Brain Behav 10(4):465-472. https://doi.org/10. 1111/j.1601-183X.2011.00688.x

4. Arnold AP, Reue K, Eghbali M, Vilain E, Chen X, Ghahramani N et al (2016) The importance of having two X chromosomes. Philos Trans R Soc Lond B Biol Sci 371(1688):20150113. https://doi. org/10.1098/rstb.2015.0113

5. Arnold AP (2017) Sex differences in the age of genetics. In: Pfaff DW, Joëls M (eds) Hormones, brain, and behavior, 3rd edn. Academic Press, Elsevier, Canada, pp 33-48

6. Graves JA (2006) Sex chromosome specialization and degeneration in mammals. Cell 124(5):901-914. https://doi.org/10.1016/j. cell.2006.02.024

7. Hughes JF, Page DC (2015) The biology and evolution of Mammalian Y Chromosomes. Annu Rev Genet 49:507-527. https:// doi.org/10.1146/annurev-genet-112414-055311

8. Lyon MF (1961) Gene action in the X-chromosome of the mouse (Mus musculus L.). Nature 190:372-373. https://doi.org/10.1038/ $190372 \mathrm{a} 0$

9. Morey C, Avner P (2010) Genetics and epigenetics of the X chromosome. Ann N Y Acad Sci 1214:E18-33. https://doi.org/10. 1111/j.1749-6632.2010.05943.x

10. Lee JT, Bartolomei MS (2013) X-inactivation, imprinting, and long noncoding RNAs in health and disease. Cell 152(6):13081323. https://doi.org/10.1016/j.cell.2013.02.016

11. Gayen S, Maclary E, Hinten M, Kalantry S (2016) Sex-specific silencing of X-linked genes by Xist RNA. Proc Natl Acad Sci U S A 113(3):E309-318. https://doi.org/10.1073/pnas.1515971113

12. Berletch JB, Yang F, Disteche CM (2010) Escape from X inactivation in mice and humans. Genome Biol 11(6):213. https://doi.org/ 10.1186/gb-2010-11-6-213

13. Disteche CM, Berletch JB (2015) X-chromosome inactivation and escape. J Genet 94(4):591-599. https://doi.org/10.1007/ s12041-015-0574-1

14. Wolstenholme JT, Rissman EF, Bekiranov S (2013) Sexual differentiation in the developing mouse brain: contributions of sex chromosome genes. Genes Brain Behav 12(2):166-180. https:// doi.org/10.1111/gbb.12010

15. Balaton BP, Brown CJ (2016) Escape Artists of the X Chromosome. Trends Genet 32(6):348-359. https://doi.org/10.1016/j.tig. 2016.03.007

16. Hong S, Cho YW, Yu LR, Yu H, Veenstra TD, Ge K (2007) Identification of JmjC domain-containing UTX and JMJD3 as histone H3 lysine 27 demethylases. Proc Natl Acad Sci U S A 104(47):18439-18444. https://doi.org/10.1073/pnas.0707292104

17. Cao R, Wang L, Wang H, Xia L, Erdjument-Bromage H, Tempst $\mathrm{P}$ et al (2002) Role of histone H3 lysine 27 methylation in Polycomb-group silencing. Science 298(5595):1039-1043. https://doi. org/10.1126/science.1076997

18. Bernstein BE, Mikkelsen TS, Xie X, Kamal M, Huebert DJ, Cuff $\mathrm{J}$ et al (2006) A bivalent chromatin structure marks key developmental genes in embryonic stem cells. Cell 125(2):315-326. https://doi.org/10.1016/j.cell.2006.02.041 
19. Shen $\mathrm{H}, \mathrm{Xu}$ W, Lan F (2017) Histone lysine demethylases in mammalian embryonic development. Exp Mol Med 49(4):e325. https:// doi.org/10.1038/emm.2017.57

20. Gazova I, Lengeling A, Summers KM (2019) Lysine demethylases KDM6A and UTY: the X and Y of histone demethylation. Mol Genet Metab 127(1):31-44. https://doi.org/10.1016/j.ymgme. 2019.04.012

21. Agger K, Cloos PA, Christensen J, Pasini D, Rose S, Rappsilber J et al (2007) UTX and JMJD3 are histone H3K27 demethylases involved in HOX gene regulation and development. Nature 449(7163):731-734. https://doi.org/10.1038/nature06145

22. Lan F, Bayliss PE, Rinn JL, Whetstine JR, Wang JK, Chen S et al (2007) A histone H3 lysine 27 demethylase regulates animal posterior development. Nature 449(7163):689-694. https://doi.org/ 10.1038 /nature06192

23. Lei X, Jiao J (2018) UTX affects neural stem cell proliferation and differentiation through PTEN signaling. Stem Cell Reports 10(4):1193-1207. https://doi.org/10.1016/j.stemcr.2018.02.008

24. Yang X, Xu B, Mulvey B, Evans M, Jordan S, Wang YD et al (2019) Differentiation of human pluripotent stem cells into neurons or cortical organoids requires transcriptional co-regulation by UTX and 53BP1. Nat Neurosci 22(3):362-373. https://doi.org/ 10.1038/s41593-018-0328-5

25. Shan Y, Zhang Y, Zhao Y, Wang T, Zhang J, Yao J et al (2020) JMJD3 and UTX determine fidelity and lineage specification of human neural progenitor cells. Nat Commun 11(1):382. https:// doi.org/10.1038/s41467-019-14028-x

26. Subhramanyam CS, Cao Q, Wang C, Heng ZSL, Zhou Z, Hu Q (2020) Role of PIWI-like 4 in modulating neuronal differentiation from human embryonal carcinoma cells. RNA Biol 17:1-12. https://doi.org/10.1080/15476286.2020.1757896

27. Tang GB, Zeng YQ, Liu PP, Mi TW, Zhang SF, Dai SK et al (2017) The Histone H3K27 Demethylase UTX Regulates Synaptic Plasticity and Cognitive Behaviors in Mice. Front Mol Neurosci 10:267. https://doi.org/10.3389/fnmol.2017.00267

28. Tang QY, Zhang SF, Dai SK, Liu C, Wang YY, Du HZ et al (2020) UTX regulates human neural differentiation and dendritic morphology by resolving bivalent promoters. Stem Cell Reports. https://doi.org/10.1016/j.stemcr.2020.06.015

29. Niikawa N, Kuroki Y, Kajii T, Matsuura N, Ishikiriyama S, Tonoki $\mathrm{H}$ et al (1988) Kabuki make-up (Niikawa-Kuroki) syndrome: a study of 62 patients. Am J Med Genet 31(3):565-589. https://doi. org/10.1002/ajmg.1320310312

30. Van Laarhoven PM, Neitzel LR, Quintana AM, Geiger EA, Zackai EH, Clouthier DE et al (2015) Kabuki syndrome genes KMT2D and KDM6A: functional analyses demonstrate critical roles in craniofacial, heart and brain development. Hum Mol Genet 24(15):4443-4453. https://doi.org/10.1093/hmg/ddv180

31. Adam MP, Banka S, Bjornsson HT, Bodamer O, Chudley AE, Harris J et al (2019) Kabuki syndrome: international consensus diagnostic criteria. J Med Genet 56(2):89-95. https://doi.org/10. 1136/jmedgenet-2018-105625

32. Lovell-Badge R, Robertson E (1990) XY female mice resulting from a heritable mutation in the primary testis-determining gene. Tdy Development 109(3):635-646

33. Mahadevaiah SK, Odorisio T, Elliott DJ, Rattigan A, Szot M, Laval SH et al (1998) Mouse homologues of the human AZF candidate gene RBM are expressed in spermatogonia and spermatids, and map to a Y chromosome deletion interval associated with a high incidence of sperm abnormalities. Hum Mol Genet 7(4):715-727. https://doi.org/10.1093/hmg/7.4.715

34. Scerbo MJ, Freire-Regatillo A, Cisternas CD, Brunotto M, Arevalo MA, Garcia-Segura LM et al (2014) Neurogenin 3 mediates sex chromosome effects on the generation of sex differences in hypothalamic neuronal development. Front Cell Neurosci 8:188. https://doi.org/10.3389/fncel.2014.00188
35. Cisternas CD, Cabrera Zapata LE, Mir FR, Scerbo MJ, Arevalo MA, Garcia-Segura LM et al (2020) Estradiol-dependent axogenesis and $\mathrm{Ngn} 3$ expression are determined by XY sex chromosome complement in hypothalamic neurons. Sci Rep 10(1):8223. https://doi.org/10.1038/s41598-020-65183-x

36. Carruth LL, Reisert I, Arnold AP (2002) Sex chromosome genes directly affect brain sexual differentiation. Nat Neurosci 5(10):933-934. https://doi.org/10.1038/nn922

37. De Vries GJ, Rissman EF, Simerly RB, Yang LY, Scordalakes EM, Auger CJ et al (2002) A model system for study of sex chromosome effects on sexually dimorphic neural and behavioral traits. J Neurosci 22(20):9005-9014

38. Gatewood JD, Wills A, Shetty S, Xu J, Arnold AP, Burgoyne PS et al (2006) Sex chromosome complement and gonadal sex influence aggressive and parental behaviors in mice. J Neurosci 26(8):2335-2342. https://doi.org/10.1523/JNEUROSCI.374305.2006

39. Dadam FM, Caeiro XE, Cisternas CD, Macchione AF, Cambiasso MJ, Vivas L (2014) Effect of sex chromosome complement on sodium appetite and Fos-immunoreactivity induced by sodium depletion. Am J Physiol Regul Integr Comp Physiol 306(3):R175-184. https://doi.org/10.1152/ajpregu.00447.2013

40. Cisternas CD, Cabrera Zapata LE, Arevalo MA, Garcia-Segura LM, Cambiasso MJ (2017) Regulation of aromatase expression in the anterior amygdala of the developing mouse brain depends on ERbeta and sex chromosome complement. Sci Rep 7(1):5320. https://doi.org/10.1038/s41598-017-05658-6

41. Cisternas CD, Tome K, Caeiro XE, Dadam FM, Garcia-Segura LM, Cambiasso MJ (2015) Sex chromosome complement determines sex differences in aromatase expression and regulation in the stria terminalis and anterior amygdala of the developing mouse brain. Mol Cell Endocrinol 414:99-110. https://doi.org/ 10.1016/j.mce.2015.07.027

42. O'Shaughnessy PJ, Baker PJ, Johnston H (2006) The foetal Leydig cell-differentiation, function and regulation. Int $\mathbf{J}$ Androl 29(1):90-95. https://doi.org/10.1111/j.1365-2605.2005.00555.x (discussion 105-108)

43. Berthois Y, Katzenellenbogen JA, Katzenellenbogen BS (1986) Phenol red in tissue culture media is a weak estrogen: implications concerning the study of estrogen-responsive cells in culture. Proc Natl Acad Sci U S A 83(8):2496-2500. https://doi. org/10.1073/pnas.83.8.2496

44. Cabrera Zapata LE, Bollo M, Cambiasso MJ (2019) Estradiolmediated axogenesis of hypothalamic neurons requires ERK1/2 and ryanodine receptors-dependent intracellular $\mathrm{Ca}(2+)$ rise in male rats. Front Cell Neurosci 13:122. https://doi.org/10.3389/ fncel.2019.00122

45. Sholl DA (1953) Dendritic organization in the neurons of the visual and motor cortices of the cat. J Anat 87(4):387-406

46. Garcia-Segura LM, Perez-Marquez J (2014) A new mathematical function to evaluate neuronal morphology using the Sholl analysis. J Neurosci Methods 226:103-109. https://doi.org/10. 1016/j.jneumeth.2014.01.016

47. Meijering E, Jacob M, Sarria JC, Steiner P, Hirling H, Unser $M$ (2004) Design and validation of a tool for neurite tracing and analysis in fluorescence microscopy images. Cytometry A 58(2):167-176. https://doi.org/10.1002/cyto.a.20022

48. Kruidenier L, Chung CW, Cheng Z, Liddle J, Che K, Joberty G et al (2012) A selective jumonji H3K27 demethylase inhibitor modulates the proinflammatory macrophage response. Nature 488(7411):404-408. https://doi.org/10.1038/nature11262

49. Hofstetter C, Kampka JM, Huppertz S, Weber H, Schlosser A, Muller AM et al (2016) Inhibition of KDM6 activity during murine ESC differentiation induces DNA damage. J Cell Sci 129(4):788-803. https://doi.org/10.1242/jcs.175174 
50. Salama-Cohen P, Arevalo MA, Grantyn R, Rodriguez-Tebar A (2006) Notch and NGF/p75NTR control dendrite morphology and the balance of excitatory/inhibitory synaptic input to hippocampal neurones through Neurogenin 3. J Neurochem 97(5):1269-1278. https://doi.org/10.1111/j.1471-4159.2006.03783.x

51. Ruiz-Palmero I, Simon-Areces J, Garcia-Segura LM, Arevalo MA (2011) Notch/neurogenin 3 signalling is involved in the neuritogenic actions of oestradiol in developing hippocampal neurones. J Neuroendocrinol 23(4):355-364. https://doi.org/10.1111/j.13652826.2011.02110.x

52. McEwen BS, Davis PG, Parsons B, Pfaff DW (1979) The brain as a target for steroid hormone action. Annu Rev Neurosci 2:65-112. https://doi.org/10.1146/annurev.ne.02.030179.000433

53. McEwen BS (1981) Neural gonadal steroid actions. Science 211(4488):1303-1311. https://doi.org/10.1126/science.6259728

54. Zechner U, Wilda M, Kehrer-Sarwatzki H, Vogel W, Hameister $\mathrm{R}$ (2001) A high density of X-linked genes for general cognitive ability: a run-away process shaping human evolution? Trends Genet 17(12):697-701. https://doi.org/10.1016/s0168-9525(01) 02446-5

55. Ross MT, Grafham DV, Coffey AJ, Scherer S, McLay K, Muzny $\mathrm{D}$ et al (2005) The DNA sequence of the human $\mathrm{X}$ chromosome. Nature 434(7031):325-337. https://doi.org/10.1038/nature03440

56. Nguyen DK, Disteche CM (2006) High expression of the mammalian X chromosome in brain. Brain Res 1126(1):46-49. https:// doi.org/10.1016/j.brainres.2006.08.053

57. Peeters SB, Cotton AM, Brown CJ (2014) Variable escape from $\mathrm{X}$-chromosome inactivation: identifying factors that tip the scales towards expression. BioEssays 36(8):746-756. https://doi.org/10. 1002/bies.201400032

58. Navarro-Cobos MJ, Balaton BP, Brown CJ (2020) Genes that escape from X-chromosome inactivation: potential contributors to Klinefelter syndrome. Am J Med Genet C Semin Med Genet 184(2):226-238. https://doi.org/10.1002/ajmg.c. 31800

59. Yang F, Babak T, Shendure J, Disteche CM (2010) Global survey of escape from $X$ inactivation by RNA-sequencing in mouse. Genome Res 20(5):614-622. https://doi.org/10.1101/gr.103200. 109

60. Cotton AM, Ge B, Light N, Adoue V, Pastinen T, Brown CJ (2013) Analysis of expressed SNPs identifies variable extents of expression from the human inactive $\mathrm{X}$ chromosome. Genome Biol 14(11):R122. https://doi.org/10.1186/gb-2013-14-11-r122

61. Berletch JB, Ma W, Yang F, Shendure J, Noble WS, Disteche $\mathrm{CM}$ et al (2015) Escape from $\mathrm{X}$ inactivation varies in mouse tissues. PLoS Genet 11(3):e1005079. https://doi.org/10.1371/journ al.pgen.1005079

62. Marks H, Kerstens HH, Barakat TS, Splinter E, Dirks RA, van Mierlo G et al (2015) Dynamics of gene silencing during X inactivation using allele-specific RNA-seq. Genome Biol 16:149. https://doi.org/10.1186/s13059-015-0698-x

63. Qu K, Zaba LC, Giresi PG, Li R, Longmire M, Kim YH et al (2015) Individuality and variation of personal regulomes in primary human T cells. Cell Syst 1(1):51-61. https://doi.org/10. 1016/j.cels.2015.06.003

64. Tukiainen T, Villani AC, Yen A, Rivas MA, Marshall JL, Satija $\mathrm{R}$ et al (2017) Landscape of $\mathrm{X}$ chromosome inactivation across human tissues. Nature 550(7675):244-248. https://doi.org/10. 1038/nature24265

65. Greenfield A, Carrel L, Pennisi D, Philippe C, Quaderi N, Siggers $P$ et al (1998) The UTX gene escapes X inactivation in mice and humans. Hum Mol Genet 7(4):737-742. https://doi.org/10.1093/ $\mathrm{hmg} / 7.4 .737$

66. Xu J, Burgoyne PS, Arnold AP (2002) Sex differences in sex chromosome gene expression in mouse brain. Hum Mol Genet 11(12):1409-1419. https://doi.org/10.1093/hmg/11.12.1409
67. Armoskus C, Moreira D, Bollinger K, Jimenez O, Taniguchi S, Tsai HW (2014) Identification of sexually dimorphic genes in the neonatal mouse cortex and hippocampus. Brain Res 1562:23-38. https://doi.org/10.1016/j.brainres.2014.03.017

68. Xu J, Deng X, Watkins R, Disteche CM (2008) Sex-specific differences in expression of histone demethylases Utx and Uty in mouse brain and neurons. J Neurosci 28(17):4521-4527. https:// doi.org/10.1523/JNEUROSCI.5382-07.2008

69. Abdelhaleem M (2005) RNA helicases: regulators of differentiation. Clin Biochem 38(6):499-503. https://doi.org/10.1016/j.clinb iochem.2005.01.010

70. Garbelli A, Beermann S, Di Cicco G, Dietrich U, Maga G (2011) A motif unique to the human DEAD-box protein DDX3 is important for nucleic acid binding, ATP hydrolysis, RNA/DNA unwinding and HIV-1 replication. PLoS ONE 6(5):e19810. https://doi. org/10.1371/journal.pone.0019810

71. Cruciat CM, Dolde C, de Groot RE, Ohkawara B, Reinhard C, Korswagen HC et al (2013) RNA helicase DDX3 is a regulatory subunit of casein kinase 1 in Wnt-beta-catenin signaling. Science 339(6126):1436-1441. https://doi.org/10.1126/science.1231499

72. Snijders Blok L, Madsen E, Juusola J, Gilissen C, Baralle D, Reijnders MR et al (2015) Mutations in DDX3X are a common cause of unexplained intellectual disability with gender-specific effects on Wnt signaling. Am J Hum Genet 97(2):343-352. https://doi. org/10.1016/j.ajhg.2015.07.004

73. Ehrmann IE, Ellis PS, Mazeyrat S, Duthie S, Brockdorff N, Mattei MG et al (1998) Characterization of genes encoding translation initiation factor eIF-2gamma in mouse and human: sex chromosome localization, escape from X-inactivation and evolution. Hum Mol Genet 7(11):1725-1737. https://doi.org/10.1093/hmg/7.11. 1725

74. Gebauer F, Hentze MW (2004) Molecular mechanisms of translational control. Nat Rev Mol Cell Biol 5(10):827-835. https://doi. org/10.1038/nrm1488

75. McCarthy MM (2008) Estradiol and the developing brain. Physiol Rev 88(1):91-124. https://doi.org/10.1152/physrev.00010.2007

76. McCarthy MM, Auger AP, Perrot-Sinal TS (2002) Getting excited about GABA and sex differences in the brain. Trends Neurosci 25(6):307-312. https://doi.org/10.1016/s0166-2236(02)02182-3

77. Arevalo MA, Ruiz-Palmero I, Scerbo MJ, Acaz-Fonseca E, Cambiasso MJ, Garcia-Segura LM (2012) Molecular mechanisms involved in the regulation of neuritogenesis by estradiol: recent advances. J Steroid Biochem Mol Biol 131(1-2):52-56. https:// doi.org/10.1016/j.jsbmb.2011.09.004

78. Azcoitia I, Barreto GE, Garcia-Segura LM (2019) Molecular mechanisms and cellular events involved in the neuroprotective actions of estradiol. Analysis of sex differences. Front Neuroendocrinol 55:100787. https://doi.org/10.1016/j.yfrne.2019.100787

79. Cambiasso MJ, Diaz H, Caceres A, Carrer HF (1995) Neuritogenic effect of estradiol on rat ventromedial hypothalamic neurons co-cultured with homotopic or heterotopic glia. J Neurosci Res 42(5):700-709. https://doi.org/10.1002/jnr.490420513

80. Cambiasso MJ, Colombo JA, Carrer HF (2000) Differential effect of oestradiol and astroglia-conditioned media on the growth of hypothalamic neurons from male and female rat brains. Eur J Neurosci 12(7):2291-2298. https://doi.org/10.1046/j.1460-9568.2000. 00120.x

81. Carrer HF, Cambiasso MJ (2002) Sexual differentiation of the brain: genes, estrogen, and neurotrophic factors. Cell Mol Neurobiol 22(5-6):479-500. https://doi.org/10.1023/a:1021825317546

82. Reisert I, Engele J, Pilgrim C (1989) Early sexual differentiation of diencephalic dopaminergic neurons of the rat in vitro. Cell Tissue Res 255(2):411-417. https://doi.org/10.1007/BF00224125

83. Ruiz-Palmero I, Ortiz-Rodriguez A, Melcangi RC, Caruso D, Garcia-Segura LM, Rune GM et al (2016) Oestradiol synthesized 
by female neurons generates sex differences in neuritogenesis. Sci Rep 6:31891. https://doi.org/10.1038/srep31891

84. Shpargel KB, Sengoku T, Yokoyama S, Magnuson T (2012) UTX and UTY demonstrate histone demethylase-independent function in mouse embryonic development. PLoS Genet 8(9):e1002964. https://doi.org/10.1371/journal.pgen.1002964

85. Walport LJ, Hopkinson RJ, Vollmar M, Madden SK, Gileadi C, Oppermann U et al (2014) Human UTY(KDM6C) is a male-specific N-methyl lysyl demethylase. J Biol Chem 289(26):1830218313. https://doi.org/10.1074/jbc.M114.555052

86. Welstead GG, Creyghton MP, Bilodeau S, Cheng AW, Markoulaki S, Young RA et al (2012) X-linked H3K27me3 demethylase Utx is required for embryonic development in a sex-specific manner. Proc Natl Acad Sci U S A 109(32):13004-13009. https://doi.org/ 10.1073/pnas.1210787109

87. Shpargel KB, Starmer J, Wang C, Ge K, Magnuson T (2017) UTX-guided neural crest function underlies craniofacial features of Kabuki syndrome. Proc Natl Acad Sci U S A 114(43):E9046E9055. https://doi.org/10.1073/pnas.1705011114

88. Salama-Cohen P, Arevalo MA, Meier J, Grantyn R, RodriguezTebar A (2005) NGF controls dendrite development in hippocampal neurons by binding to p75NTR and modulating the cellular targets of Notch. Mol Biol Cell 16(1):339-347. https://doi.org/10. 1091/mbc.e04-05-0438

89. Carcagno AL, Di Bella DJ, Goulding M, Guillemot F, Lanuza GM (2014) Neurogenin3 restricts serotonergic neuron differentiation to the hindbrain. J Neurosci 34(46):15223-15233. https://doi.org/ 10.1523/JNEUROSCI.3403-14.2014
90. Simon-Areces J, Dopazo A, Dettenhofer M, Rodriguez-Tebar A, Garcia-Segura LM, Arevalo MA (2011) Formin1 mediates the induction of dendritogenesis and synaptogenesis by neurogenin 3 in mouse hippocampal neurons. PLoS ONE 6(7):e21825. https:// doi.org/10.1371/journal.pone.0021825

91. Pelling M, Anthwal N, McNay D, Gradwohl G, Leiter AB, Guillemot $F$ et al (2011) Differential requirements for neurogenin 3 in the development of POMC and NPY neurons in the hypothalamus. Dev Biol 349(2):406-416. https://doi.org/10.1016/j.ydbio.2010. 11.007

92. Beyer C, Wozniak A, Hutchison JB (1993) Sex-specific aromatization of testosterone in mouse hypothalamic neurons. Neuroendocrinology 58(6):673-681. https://doi.org/10.1159/000126608

93. Karolczak M, Küppers E, Beyer C (1998) Developmental expression and regulation of aromatase- and 5alpha-reductase type I mRNA in the male and female mouse hypothalamus. J Neuroendocrinol 10(4):267-274. https://doi.org/10.1046/j.1365-2826. 1998.00200.x

94. Karolczak M, Beyer C (1998) Developmental sex differences in estrogen receptor-beta mRNA expression in the mouse hypothalamus/preoptic region. Neuroendocrinology 68(4):229-234. https:// doi.org/10.1159/000054370

Publisher's Note Springer Nature remains neutral with regard to jurisdictional claims in published maps and institutional affiliations. 